\title{
The developing story of Sprouty and cancer
}

\author{
Samar Masoumi-Moghaddam • Afshin Amini • \\ David Lawson Morris
}

Published online: 18 April 2014

(C) The Author(s) 2014. This article is published with open access at Springerlink.com

\begin{abstract}
Sprouty proteins are evolutionarily conserved modulators of MAPK/ERK pathway. Through interacting with an increasing number of effectors, mediators, and regulators with ultimate influence on multiple targets within or beyond ERK, Sprouty orchestrates a complex, multilayered regulatory system and mediates a crosstalk among different signaling pathways for a coordinated cellular response. As such, Sprouty has been implicated in various developmental and physiological processes. Evidence shows that ERK is aberrantly activated in malignant conditions. Accordingly, Sprouty deregulation has been reported in different cancer types and shown to impact cancer development, progression, and metastasis. In this article, we have tried to provide an overview of the current knowledge about the Sprouty physiology and its regulatory functions in health, as well as an updated review of the Sprouty status in cancer. Putative implications of Sprouty in cancer biology, their clinical relevance, and their proposed applications are also revisited. As a developing story, however, role of Sprouty in cancer remains to be further elucidated.
\end{abstract}

Keywords Sprouty $\cdot$ Cancer $\cdot$ MAPK/ERK $\cdot$ RTK $\cdot$ Growth factors

$\begin{array}{ll}\text { Abbreviations } & \\ \text { ARMS } & \text { Alveolar subtype of rhabdomyosarcoma } \\ \text { BCR } & \text { B-cell receptor } \\ \text { BDNF } & \text { Brain-derived neurotrophic factor } \\ \text { BPH } & \text { Benign prostatic hyperplasia } \\ \text { Cav-1 } & \text { Caveolin-1 } \\ \text { CBD } & \text { c-Cbl binding domain }\end{array}$

S. Masoumi-Moghaddam $(\bowtie) \cdot$ A. Amini $\cdot$ D. L. Morris UNSW Department of Surgery, University of New South Wales, St George Hospital, Kogarah, Sydney, NSW 2217, Australia e-mail: samar.masoumi@gmail.com

$\begin{array}{ll}\text { c-Cbl } & \text { Canonical Casitas B-lineage lymphoma } \\ \text { ccRCC } & \text { Clear cell renal cell carcinomas } \\ \text { cDNA } & \text { Complementary DNA } \\ \text { CRD } & \text { Cysteine-rich domain } \\ \text { CREB } & \text { cAMP response element-binding protein } \\ \text { CtBP } & \text { C-terminal binding protein } \\ \text { dSpry } & \text { Drosophila Sprouty } \\ \text { DYRK1A } & \text { Dual-specificity tyrosine phosphorylation- } \\ & \text { regulated kinase 1A } \\ \text { EGF } & \text { Epidermal growth factor } \\ \text { EGFR } & \text { Epidermal growth factor receptor } \\ \text { ERK } & \text { Extracellular signal-regulated kinase } \\ \text { ERMS } & \text { Embryonic subtype of rhabdomyosarcoma } \\ \text { EST } & \text { Expressed Sequence Tag } \\ \text { FGF } & \text { Fibroblast growth factor } \\ \text { FRS2 } \alpha & \text { Fibroblast growth factor receptor substrate 2 } \\ \text { G } \alpha_{o} & \text { G protein } \alpha_{o} \\ \text { GDNF } & \text { Glial cell line-derived neurotrophic factor } \\ \text { GISTs } & \text { Gastrointestinal stromal tumors } \\ \text { GRIN } & \text { G protein-regulated inducer of neurite } \\ & \text { outgrowth } \\ \text { GSK3B } & \text { Glycogen synthase kinase } 3 \text { beta } \\ \text { HCC } & \text { Hepatocellular carcinoma } \\ \text { HCCP } & \text { Hepatocellular carcinoma with poorer } \\ & \text { outcome } \\ \text { HDM2 } & \text { Human double minute 2 } \\ \text { HER2 } & \text { Human epidermal growth factor receptor 2 } \\ \text { HGF } & \text { Hepatocyte growth factor } \\ \text { Hrs } & \text { Hepatocyte growth factor-regulated tyrosine } \\ \text { kinase substrate } \\ \text { hSpry } & \text { Human Sprouty } \\ \text { KITLG } & \text { The ligand for the receptor tyrosine kinase } \\ & \text { c-KIT } \\ \text { LOH } & \text { Loss of heterozygosity } \\ \text { MAPK } & \text { Mitogen-activated protein kinase } \\ \text { MAP2K } & \text { MAPK kinases } \\ & \end{array}$




\begin{tabular}{|c|c|}
\hline MAP3K & MAPK-kinase kinase \\
\hline MEF & Mouse embryonic fibroblasts \\
\hline MEK & MAPK/ERK kinases \\
\hline Mnk1 & MAPK-interacting kinase 1 \\
\hline MPNST & Malignant peripheral nerve sheath tumors \\
\hline mRNA & Messenger RNA \\
\hline mSpry & Mouse Sprouty \\
\hline MTC & Medullary thyroid carcinoma \\
\hline myr-Akt & Myristoylated Akt \\
\hline NEEC & Nonendometrioid carcinomas \\
\hline NF1 & Neurofibromin 1 \\
\hline NGF & Nerve growth factor \\
\hline NSCLC & Non-small cell lung cancer \\
\hline PDCD4 & Programmed cell death 4 \\
\hline PDGF & Platelet-derived growth factor \\
\hline PHD & Prolyl hydroxylase domain protein \\
\hline PI3K & Phosphatidylinositol 3-kinase \\
\hline PIN & Prostatic intraepithelial neoplasia \\
\hline PIP2 & Phosphatidylinositol 4,5-bisphosphate \\
\hline PIP3 & Phosphatidylinositol 3,4,5-trisphosphate \\
\hline PKC & Protein kinase $\mathrm{C}$ \\
\hline PKM2 & Pyruvate kinase M2 \\
\hline PLC & Phospholipase C \\
\hline PMA & Phorbol 12-myristate-13-acetate \\
\hline PP2A & Protein phosphatase 2A \\
\hline $\operatorname{PPAR} \gamma$ & $\begin{array}{l}\text { Peroxisome proliferator-activated receptor } \\
\text { gamma }\end{array}$ \\
\hline PTEN & Phosphatase and tensin homolog \\
\hline PTP1B & Protein tyrosine phosphatase $1 \mathrm{~B}$ \\
\hline pVHL & von Hippel-Lindau protein \\
\hline RMS & Rhabdomyosarcoma \\
\hline ROS & Reactive oxygen species \\
\hline RTK & Receptor tyrosine kinase \\
\hline S1P & Sphingosine-1-phosphate \\
\hline SHP2 & $\begin{array}{l}\text { Src homology 2-containing phosphotyrosine } \\
\text { phosphatase }\end{array}$ \\
\hline Siah2 & Seven in Absentia homolog 2 \\
\hline SP1 & Specificity protein 1 \\
\hline Spry1-4 & Sprouty protein isoforms $1-4$ \\
\hline SRM & Serine-rich motif \\
\hline TCL1-tg & T-cell leukemia 1-transgenic \\
\hline TCR & T cell receptor \\
\hline TESK1 & Testicular protein kinase 1 \\
\hline TGCT & Testicular germ cell tumors \\
\hline TGF $\beta 1$ & Transforming growth factor-beta1 \\
\hline TNF- $\alpha$ & Tumor necrosis factor-alpha \\
\hline Tsg101 & Tumor susceptibility gene 101 protein \\
\hline uPA & Urokinase-type plasminogen activator \\
\hline uPAR & $\begin{array}{l}\text { Urokinase-type plasminogen activator } \\
\text { receptor }\end{array}$ \\
\hline VEGF & Vascular endothelial growth factor \\
\hline WT & Wild type \\
\hline WT1 & Wilms tumor suppressor 1 \\
\hline
\end{tabular}

$\begin{array}{ll}\text { xSpry } & \text { Xenopus Sprouty } \\ \text { zSpry } & \text { Zebra fish Sprouty }\end{array}$

\section{Introduction}

Mitogen-activated protein kinase (MAPK) signaling pathways are among the most widespread regulatory mechanisms of the eukaryotic cell biology. The first mammalian MAPK pathway to be identified and entirely mapped is extracellular signal-regulated kinase or MAPK/ERK (hereafter ERK). ERK orchestrates a signal transduction from cell membrane molecules to the transcriptional machinery to promote cell growth, differentiation, and survival. As with other MAPKs, ERK represents a three-tiered kinase cascade composed of the sequentially-acting kinases. ERK is activated by a wide range of extracellular signals including growth factors, cytokines, hormones, and neurotransmitters. Signal transduction is initiated when a ligand binds its transmembrane receptor tyrosine kinase (RTK) and thereby activates Ras, a small G protein anchored to the plasma membrane. Ras subsequently recruits from the cytosol to the cell membrane and activates Raf serine/threonine-specific kinases of MAPK-kinase kinase (MAP3K) family. Through serine/threonine phosphorylation, Raf activates a family of dual specificity kinases known as MAPK kinases (MAP2K) or MAPK/ERK kinases (MEKs). By concomitant tyrosine and threonine phosphorylation, MEKs activate MAPK (Erk). Phosphorylated Erk eventually induces gene expression by direct and indirect targeting of transcription factors. To setup a biologically coordinated infrastructure for physiologically appropriate outcomes, ERK and its core modules are under tight, multilayered control of positive and negative regulators, including the Sprouty protein family.

Sprouty was discovered by Hacohen et al. who initially described it as a common antagonist of fibroblast growth factor (FGF) and epidermal growth factor (EGF) signaling pathways in Drosophila [1, 2]. In a search of the Expressed Sequence Tag (EST) database, they identified three human homologs of the fly gene designated $h$ Spryl-3 [1]. The fourth mammalian homolog, hSpry4, was later discovered in mice [3] and humans [4]. Emerging evidence later showed that Sprouty specifically inhibits activation of ERK in response to a wide range of trophic factors, including FGF $[5,6]$, platelet-derived growth factor (PDGF) [5], vascular endothelial growth factor (VEGF) [6], nerve growth factor (NGF) [7], brain-derived neurotrophic factor (BDNF) [8], and glial cell line-derived neurotrophic factor (GDNF) [9]. The biological functions of the Sprouty proteins have been attributed to its conserved motifs. These mainly include the N-terminal canonical Casitas B-lineage lymphoma (c-Cbl) binding domain (CBD) containing a key tyrosine residue; the serine-rich motif 
(SRM); and the C-terminal cysteine-rich domain (CRD) also known as the Sprouty (or translocation) domain. Among the Sprouty isoforms, Spry2 exhibits the highest evolutionary conservation, with the human Spry 2 showing 97, 85, and $51 \%$ sequence homology, in the CRD domain, to the mouse, chick, and Drosophila protein, respectively [10]. Although Spry2 appears to be ubiquitously expressed in embryonic and adult tissues, the expression of other isoforms shows organ/tissue specificity $[4,10,11]$.

The Sprouty proteins are currently recognized as key regulators of ERK signaling that act on different levels of the pathway. Furthermore, they are part of a tightly-orchestrated regulatory mechanism where interactions with a variety of players lay the basis for a crosstalk between ERK and partner cascades. Nevertheless, aberrant activation of ERK and deregulation of Sprouty occurs in a variety of pathological conditions, including malignant transformation. In this article, complex functions of the Sprouty family under physiological conditions are revisited, altered expression of Sprouty in different cancer types and its impact on cancer development, progression, and metastasis studied by different investigators are reviewed, and clinical application of the deregulated Sprouty as a biological marker and/or a focus of targeted strategies is discussed.

\section{Sprouty: a versatile modulator with complex functionality}

Since discovery of Sprouty in 1998 [1], an expanding body of evidence has continued to support its crucial role in regulation of various physiological processes. Initial studies by Minowada et al. [10] and Tefft et al. [12] revealed that this protein family and its regulatory relationship with FGFinduced signaling are evolutionarily conserved. Through comparative genomic analysis, the linkage between the human Sprouty and FGF genes was later reported [13]. Sprouty regulates tubular morphogenesis as a fundamental process in organogenesis and angiogenesis where FGF signaling is particularly involved [14-16]. Apart from its crucial role in embryogenesis, Sprouty has been implicated in regulation of physiological events in adult organs. Table 1 summarizes a number of studies in which implication of Sprouty in developmental and physiological events has been documented.

At cellular level, Sprouty modulates key processes including proliferation, differentiation, motility, and survival through regulation of ERK and parallel pathways, as well as interaction with a number of effectors and regulators. As listed in Table 2, various regulatory effects of the Sprouty proteins in normal and neoplastic cells have been documented in literature. The Sprouty-mediated modulation, however, occurs in a cell- and context-dependent manner where a number of facts and factors, as described below, are involved in the determination of the eventual response.

\subsection{Cell and context dependency}

It is evident that cellular behavior in response to the growth factor stimulation and Sprouty-mediated regulation varies from cell to cell. For example, while Spry2 inhibits the differentiation of PC12 pheochromocytoma cells in response to FGF $[5,7]$, it promotes FGF-induced differentiation of C2C12 myoblasts [48]. Depending on the cellular context and innate physiological characteristics, different components of the RTK signalosome are activated by different ligands [73]. Moreover, strength and duration of the signal transduction are among critical determinants of cell fate in response to activation and regulation of the RTK signaling [74]. In NIH3T3 fibroblasts and PC12 cells, for example, whereas transient activation of ERK during mid-G1 phase leads to cell cycle progression and hence proliferation in the former, sustained ERK activity induces cell-cycle withdrawal and neuronal differentiation in the latter [75]. Accordingly, Sprouty was shown to inhibit proliferation of NIH3T3 cells and differentiation of $\mathrm{PC} 12$ cells in response to growth factor stimulation [5]. It will be discussed in the following sections that how Sprouty modulates the RTK signaling depending on the intersection point where it interferes as well as on its interplay with other interacting molecules.

\subsection{Growth factor dependency and pathway sensitivity}

Depending on the RTK activated and the downstream pathway(s) affected, Sprouty differentially modulates growth factor actions and thereby elicits divergent responses. Hence, Sprouty isoforms are able to selectively uncouple growth factor-induced signal transductions. In a study by Impagnatiello et al. [6] indicating an anti-proliferative effects of the overexpressed Spry1 and Spry2 on endothelial cells in the presence of FGF, VEGF, and EGF, while FGF- and VEGF-induced activation of ERK were repressed by Sprouty, EGF-activated ERK was left unaffected. It was revealed in a study by Sasaki et al. [60] that the expression of Spry2 and Spry4 in HEK293 cells inhibited FGF-induced ERK signaling but did not affect EGF or PDBu activation of ERK. Conversely, the expression of dominant negative mutants of Spry2 and Spry4 enhanced and prolonged FGF, but not EGF, activation of ERK. They later found that Spry4 suppresses VEGFinduced, Ras-independent activation of Rafl but does not affect the Ras-dependent cascade induced by EGF [76]. Furthermore, evidence supports a positive feedback loop whereby EGF stimulation of ERK signaling is potentiated and sustained by Sprouty. This paradoxical effect was initially investigated by Wong et al. [7] in PC12 cells employed as a proliferation/differentiation responsive model. It is known that 
Table 1 Sprouty implication in developmental and physiological processes reported by some investigators
dSpry Drosophila Sprouty; $h$ Spry human Sprouty; mSpry mouse Sprouty; $x$ Spry Xenopus Sprouty; zSpry zebra fish Sprouty

\begin{tabular}{|c|c|c|}
\hline Investigators & Sprouty isoform & Developmental/Adult physiological event \\
\hline Hacohen et al. [1] & dSpry & Tracheal development \\
\hline Kramer et al. [2] & dSpry & Eye development \\
\hline Minowada et al. [10] & mSpry 2 and 4 & Limb development \\
\hline Tefft et al. [12] & mSpry2 & Lung development \\
\hline Furthauer et al. [17] & zSpry4 & Midbrain development \\
\hline Zhang et al. [18] & mSpry 1,2 and 4 & Craniofacial and trunk development \\
\hline Gross et al. [19] & mSpry1 & Kidney development \\
\hline Chi et al. [20] & hSpry2 & Ureteric branching \\
\hline Lo et al. [21] & mSpry 1 and 2 & Breast development in puberty and pregnancy \\
\hline Anteby et al. [22] & hSpry 1,2 , and 3 & Placental villi sprouting \\
\hline Haimov-Kochman et al. [23] & hSpry2 & Follicle maturation and corpus luteum formation \\
\hline Lin et al. [24] & mSpry2 & Patterning of midbrain and anterior hindbrain \\
\hline Shim et al. [25] & mSpry2 & Inner ear development \\
\hline Basson et al. [26] & mSpry1 & Ureteric branching \\
\hline Boros et al. [27] & mSpry 1 and 2 & Ocular lens development \\
\hline Chi et al. [28] & mSpry2 & Male sex organogenesis \\
\hline Natanson-Yaron et al. [29] & hSpry2 & Placental villi sprouting \\
\hline Price et al. [30] & hSpry4 & Kidney development \\
\hline Gross et al. [8] & mSpry2 & Neuronal differentiation \\
\hline Shaw et al. [31] & mSpry2 & Lung development \\
\hline Laziz et al. [32] & hSpry 1,2 and 4 & Muscle regeneration \\
\hline Hamel et al. [33] & hSpry2 & Oocyte developmental competence \\
\hline Klein et al. [34] & mSpry4 (+ mSpry1 or 2) & Growth and development of rodent incisors \\
\hline Jaggi et al. [35] & mSpry4 & Pancreas development \\
\hline Wang et al. [36] & xSpry 1 & Gastrulation \\
\hline Pan et al. [37] & mSpry2 & Lens and lacrimal gland development \\
\hline Purcell et al. [38] & mSpry 1 and 2 & Temporomandibular Joint development \\
\hline Sieglitz et al. [39] & dSpry & Neuronal and glial differentiation \\
\hline Kuracha et al. [40] & mSpry 1 and 2 & Eyelid closure \\
\hline Velasco et al. [41] & hSpry2 & Endometrial gland developing and branching \\
\hline Sigurdsson et al. [42] & hSpry2 & Breast morphogenesis \\
\hline Ching et al. [43] & mSpry 1 and 2 & External genitalia development \\
\hline
\end{tabular}

FGF and NGF induce differentiation of PC12 cells into a neuron-like phenotype via sustained activation of ERK, whereas EGF stimulation transiently activates ERK and thus promotes cell proliferation $[74,77]$. Wong et al. reported that Spry1 and Spry2 inhibited differentiation of PC12 cells induced by FGF-activated ERK, yet they augmented ERK activity in response to EGF and hence promoted differentiation of PC12 cells [7]. This effect represents an intriguing role of Sprouty in protecting EGF receptor (EGFR), which will be discussed later. Using NIH3T3 and PC12 cells transfected with Spry1 or Spry2, Gross et al. [5] observed that Sprouty restricted cell proliferation and growth factor-induced differentiation, but did not promote apoptosis. The investigators found that Spry1 and Spry2 impeded FGF or PDGF stimulation of ERK, but did not affect phosphatidylinositol 3-kinase (PI3K)/AKT pathway through which many RTK-mediated survival signals are relayed. In another study, De Alvaro et al. indicated that FGF stimulation of $\mathrm{C} 2 \mathrm{C} 12$ myoblasts induces proliferation and a differentiation-defective phenotype associated with sustained activation of ERK and lack of activation of AKT. Overexpressed Spry2, however, conferred myogenic differentiation properties that were accompanied by repression of ERK and activation of AKT [48].

\subsection{Transcriptional regulation of the Sprouty expression}

ERK pathway is known to generally upregulate Sprouty [78]. However, inducibility of the Sprouty isoforms in response to the growth factor stimulation may vary in a cell type- and context-dependent manner. In an initial study by Ozaki et al., 


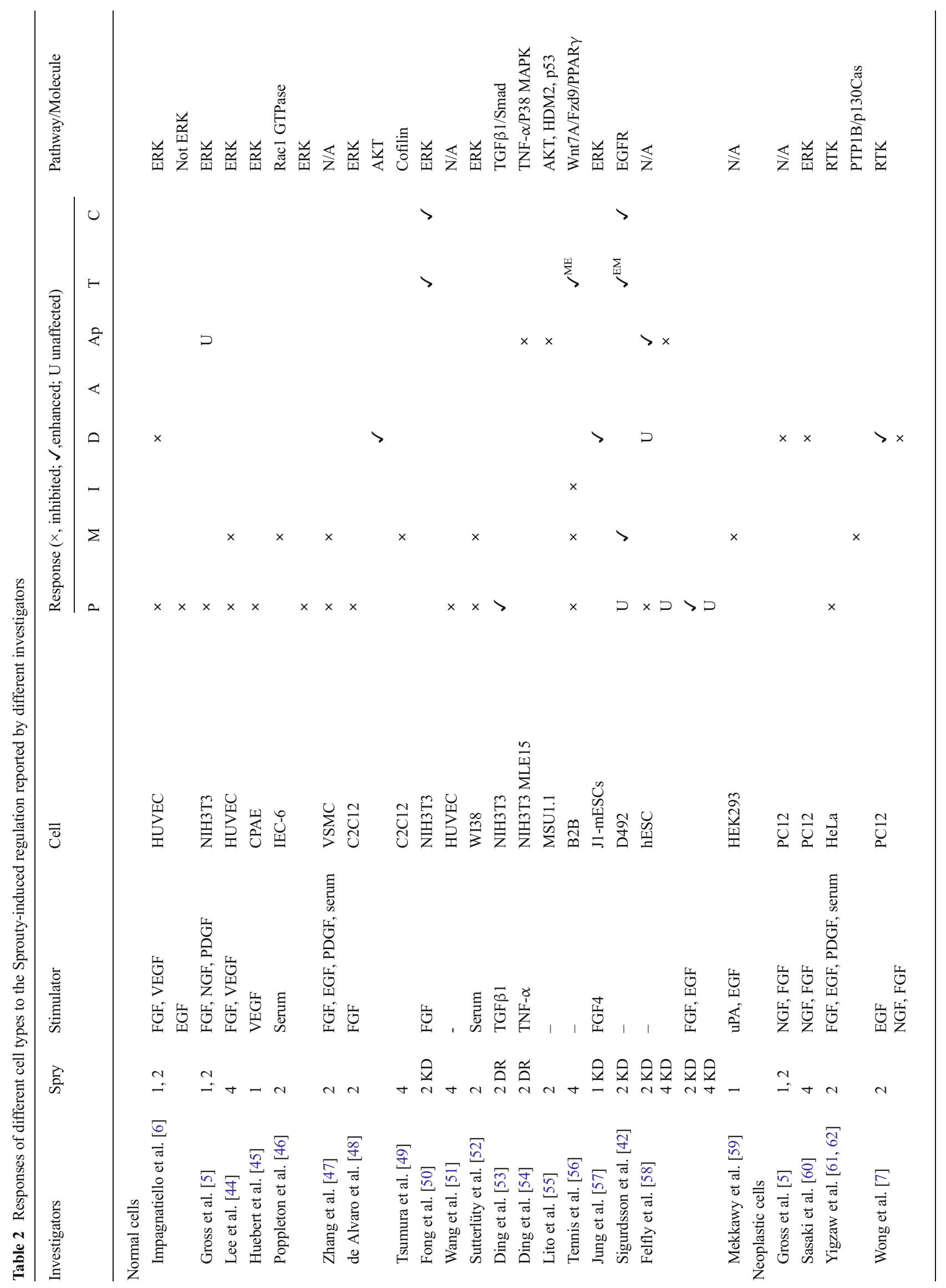




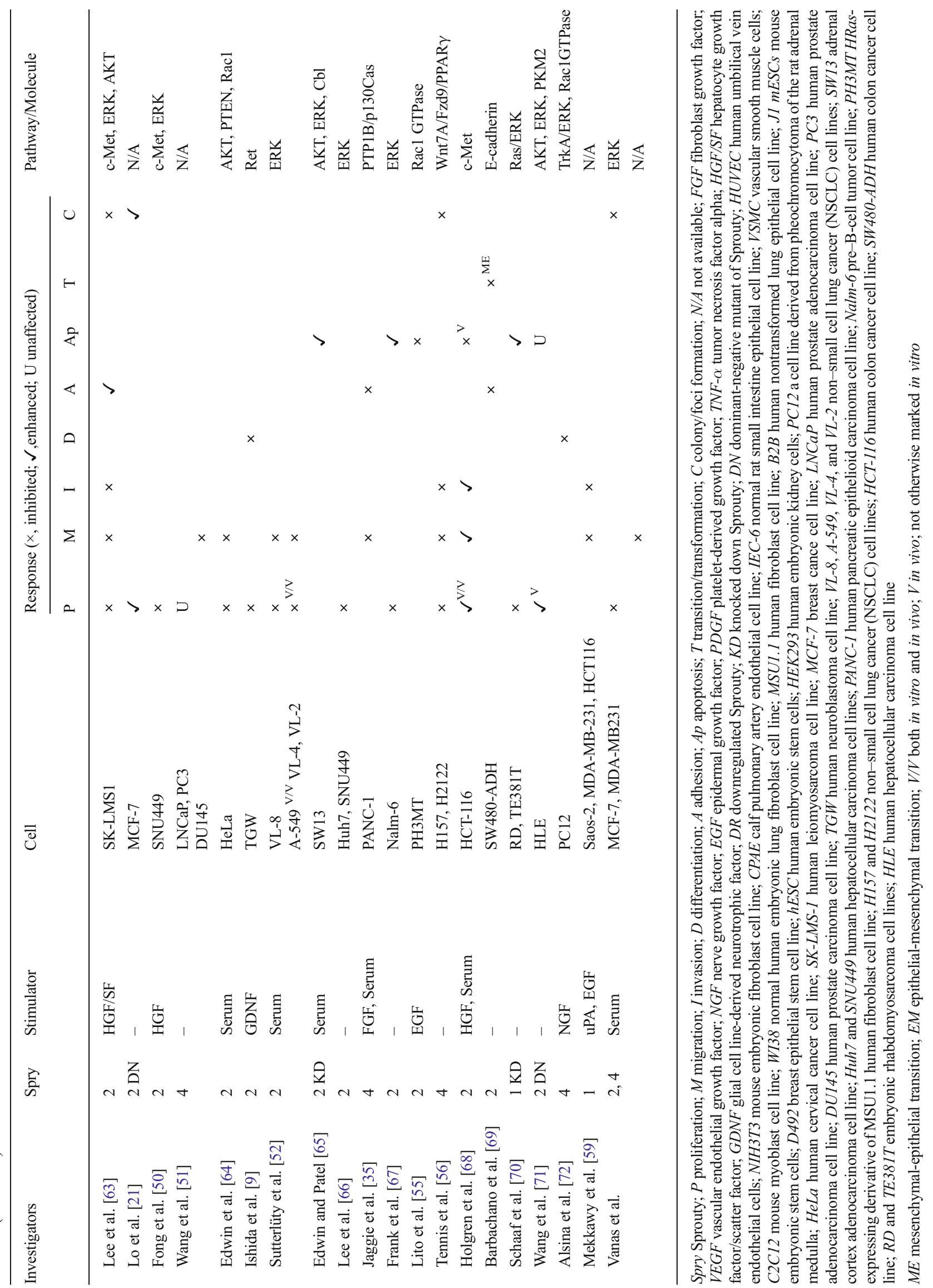


the expression of the Sprouty genes, including Spryl, was shown to be positively regulated by ERK [78]. Parallel studies consistently reported that the expression of Spry2 and Spry 4 was rapidly induced by growth factors in fibroblasts [5], endothelial cells [6], and HEK293 cells [60], yet concomitant downregulation of Spryl was observed [5, 6]. Moreover, Kral et al. [79] demonstrated that neither growth factor stimulation nor Ras activation increased the Spry1 protein levels in WI38 normal human lung fibroblasts. Since Spry1 in their cell cycle analysis with WI38 cells was constantly expressed, they concluded that mitogenic signaling is not sufficient to modulate the Spry1 expression, and that Spry1, as appeared in earlier studies $[19,80,81]$, is more likely modulated by differentiation processes. In agreement, partner pathways and mechanisms, too, have been shown to play a role in modulating transcriptional expression of the Sprouty proteins. Choi et al. [82] indicated that Spry1 is the only Sprouty isoform induced by $\mathrm{T}$ cell receptor (TCR) stimulation in murine $\mathrm{CD} 4^{+} \mathrm{T}$ cells and that ensuing expression of Spryl with dual output impacts TCR signaling depending on their differentiation state. In contrast, Frank et al. observed in mouse splenic B cells that combined activation of $\mathrm{CD} 40$ and $\mathrm{B}$ cell receptor (BCR), known as a stimulator of B-cell proliferation and survival, induces Spry2, but not Spry1, through an ERK-dependent negative feedback loop which attenuates activation of ERK, thereby implicating Spry2 in regulating antigen-induced expansion of mature B cells [67]. Ding et al. reported that transforming growth factor-betal (TGF $\beta 1$ ) signaling downregulates Spry 2 protein in Swiss 3 T3 cells in a MAPK-independent manner with possible involvement of Smad pathway [53]. Later, they also implicated tumor necrosis factor-alpha (TNF- $\alpha$ ) signaling in the Spry2 downregulation via p38 MAPK led to apoptosis of Swiss 3 T3 fibroblasts and MLE15 lung epithelial cells [54]. Different growth factor isoforms may also variably stimulate the RTK induction of the Sprouty expression. Jiang et al. observed in granulosa cells that while FGF1, FGF4, and FGF8 enhanced the expression of Spry2 and Spry4, and FGF8 additionally increased the abundance of Spry1 messenger RNA (mRNA), FGF10 and FGF18 failed to induce the Sprouty expression [83, 84]. Moreover, the presence of GC-rich regions in Spry1 [19], Spry2 [85], and Spry4 [11] promoters suggests spatiotemporal regulation of the Sprouty expression by tissue-specific transcription factors. Accordingly, the transcription factors Wilms tumor suppressor 1 (WT1) [19], cAMP response element-binding protein (CREB) and specificity protein 1 (SP1) [8], and peroxisome proliferator-activated receptor gamma (PPAR $\gamma$ ) [56] have been implicated in normal development of kidney and central nervous system, as well as in the inhibition of lung tumorigenesis via activating Spry1, Spry2, and Spry4 promoters, respectively. Also, Sabatel et al. identified Spryl as a target of the angiostatic agent $16 \mathrm{~K}$ prolactin which was shown to induce NF-kappaB-dependent upregulation of Spryl in primary and human endothelial cells. They showed that Spry1 silencing protects endothelial cells from apoptosis and induces endothelial cell adhesion, migration, and tube formation and argued that Spry1 acts as an endogenous inhibitor of angiogenesis [86].

2.4 Modulation of the Sprouty stability by post-translational mechanisms

Apart from transcriptional regulation of the protein expression, intracellular level of Sprouty is post-translationally controlled, as well. Polyubiquitylation and proteasomal degradation of active Sprouty mediated by the E3 ubiquitin ligase $\mathrm{c}-\mathrm{Cbl}$ is a tyrosine phosphorylation-dependent process that temporally limits the Sprouty intervention [87, 88]. Mason et al. showed that although Spry2/c-Cbl complex formation is dispensable for the inhibitory effect of Spry2 on the FGF-activated ERK, it mediates degradation of Spry2 in response to FGF. Thus, Spry2 accumulates to higher levels and inhibits FGF-induced signaling more efficiently in c-Cbl-null mouse embryonic fibroblasts (MEFs) than in control MEFs [89, 90]. Reporting bimodal expression of Spry2 along with sustained elevation of Spry4 during cell cycle progression, Mayer et al. [91] indicated that second phase in the expression profile of Spry2 as transient attenuation of the protein expression during late G1 is solely dependent on cell cycle-specific ubiquitination by c-Cbl. DaSilva et al. [92] showed that serine phosphorylation on Ser112 and Ser121 by MAPKinteracting kinase 1 (Mnk1) provides Spry2 with balanced phosphorylation of Tyr55 that leads to the protein stabilization. As such, mutation of theses serine residues or inhibition of Mnk1 augmented RTK-mediated phosphorylation of Tyr55, thereby enhancing c-Cbl-mediated degradation of the protein. Edwin et al. [93] reported that the HECT domain-containing E3 ubiquitin ligase Nedd4 binds and polyubiquitinates Spry2 to regulates its cellular content along with its ability to modulate RTK signaling. They found that Nedd4 requires Mnk2-dependent phosphorylation of Ser112/Ser121 for its interaction with Spry2. Another E3 ubiquitin ligase, Seven in Absentia homolog 2 (Siah2), has also been implicated in post-translational regulation of the Sprouty content. Nadeau et al. [94] indicated that coexpression of Siah2 resulted in proteasomal degradation of Spry1, Spry2, and, to a lesser extent, Spry4 in a tyrosine phosphorylation-independent manner. As with c$\mathrm{Cbl}$, it was shown that RING finger domain of Siah2 binds the N-terminal domain of Spry2 to mediate their interaction. Consistently, it was later reported that a dominantnegative Siah2 RING mutant primarily increased the Sprouty content and activity [95]. Furthermore, it was demonstrated in a study by Ding et al. on Swiss 3 T3 cells that TGF $\beta 1$ not only downregulates the expression of 
Spry2, but also induces the protein degradation via a lysosome-dependent pathway [53]. They concluded that downregulation of Spry 2 by $\operatorname{TGF} \beta 1$ at transcriptional and post-translational levels lays a basis for crosstalk between TGF $\beta 1$ signaling and EGF, as well as FGF-induced ERK in mesenchymal cells. Haigal et al. showed that hypoxia increased the Spry4 expression in several cell types through HIF-dependent transcription as well as increased mRNA stability [96]. Furthermore, Anderson et al. [97] demonstrated that prolyl hydroxylation of Spry2 by prolyl hydroxylase domain proteins (PHDs) during normoxia targets it for recognition and ubiquitination by von Hippel-Lindau (pVHL)-associated E3 ubiquitin ligase.

Transcriptional and post-translational regulation of the Sprouty cellular content is illustrated in Fig. 1.

\subsection{Regulation of the Sprouty activity}

Sprouty trafficking to and from the plasma membrane regulates subcellular localization of Sprouty and hence keeps the protein functionality under spatiotemporal control. In unstimulated cells, Sprouty is distributed throughout the cytosol, with hSpry2 being colocalized with microtubules, as well. Upon growth factor activation, Sprouty translocates to the plasma membrane, notably ruffles, where it becomes activated in association with phosphatidylinositol 4,5bisphosphate (PIP2) and the caveolin-1 (Cav-1) [6, 98-100]. Lim et al. [100] demonstrated that Sprouty binds PIP2 through its CRD domain and that this phenomenon is an essential process for regulation of ERK signaling. As the major structural protein of caveolae (specialized plasma membrane

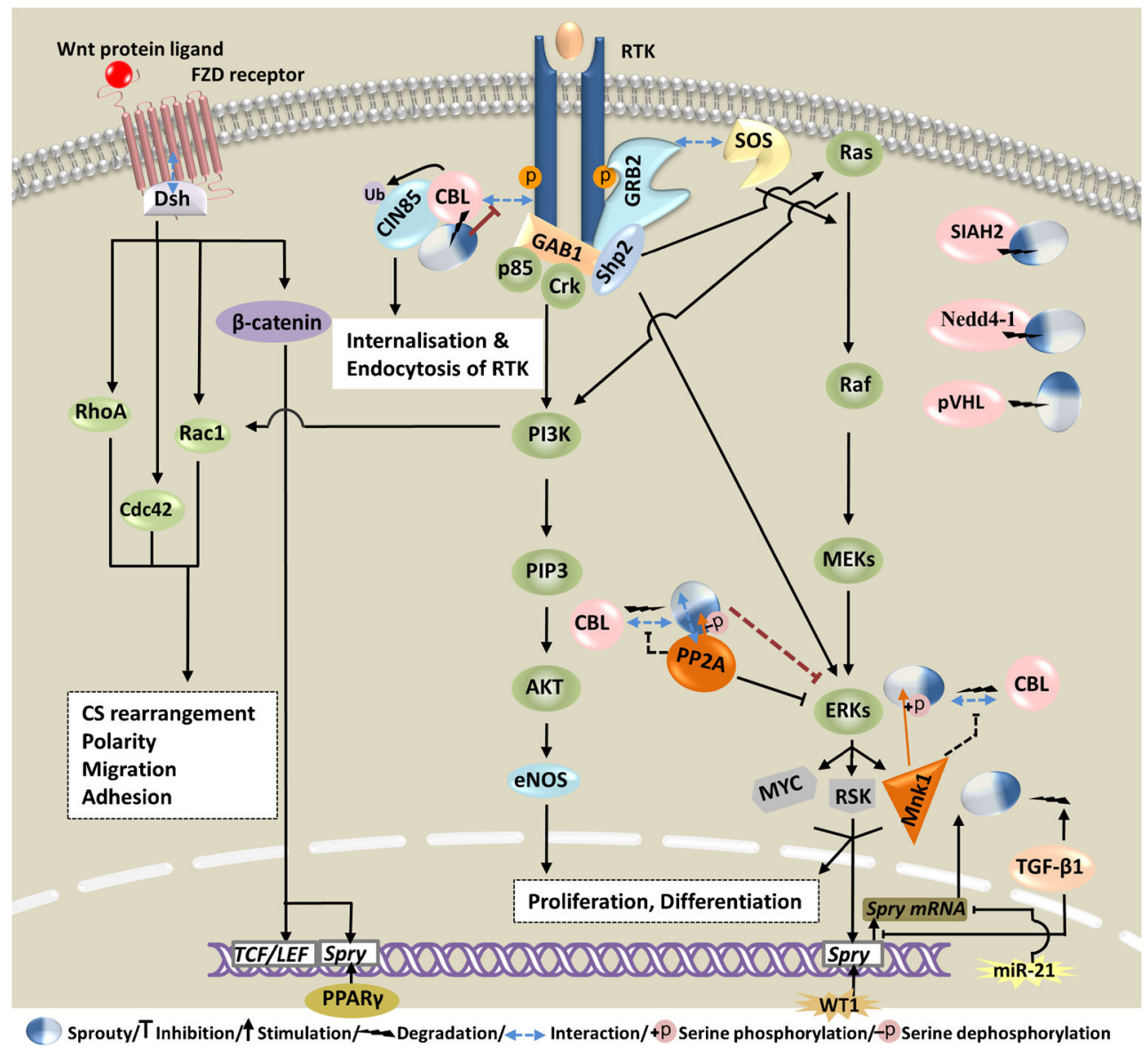

Fig. 1 Representative regulators of the Sprouty cellular content at transcriptional and post-translational level irrespective of the Sprouty isoform and cell type. $M A P K / E R K$ is the main pathway to upregulate Sprouty. Transcription factors $W T 1$ and $P P A R \gamma$ and $W n t / \beta$-catenin signaling pathway have also been shown to upregulate Sprouty. $m i R-21$ is a cancerassociated microRNA that targets and negatively regulates the Sprouty genes. $T G F \beta 1$ not only downregulates the expression of Sprouty, but also induces the protein degradation via a lysosome-dependent pathway. E3 ubiquitin ligases $c-C b l$, Siah2, NEDD4, and $p V H L$ induce degradation of Sprouty to regulate its cellular content. $P P 2 A$ competes with $\mathrm{c}-\mathrm{Cbl}$ for binding to Sprouty, thereby inhibiting c-Cbl-mediated degradation of
Sprouty. Mnkl is a positive regulator of the Sprouty stability through serine phosphorylation. $\mathrm{c}$ - $\mathrm{Cbl}$ canonical Casitas B-lineage lymphoma; FZD receptor Frizzled receptor; $m i R-21$ microRNA 21; Mnk1 MAPKinteracting kinase 1 ; NEDD4 neural precursor cell expressed, developmentally down-regulated $4 ; P P 2 A$ protein phosphatase $2 \mathrm{~A} ; P P A R \gamma$ peroxisome proliferator-activated receptor gamma; $R T K$ receptor tyrosine kinase; Siah2 Seven in Absentia homolog 2; WT1 Wilms tumor suppressor 1; CS rearrangement cytoskeletal rearrangement. In this figure, $\mathrm{C}$ and $\mathrm{N}$-terminus of the Sprouty molecule symbol are shown in white and blue, respectively 
invaginations involved in multiple cellular functions, including signal transduction), Cav-1 similarly inhibits growth factor activation of ERK in a cell density-dependent manner. At higher cell densities, Sprouty/Cav-1 interaction modulates signaling in a growth factor- and Sprouty isoform-specific manner. At lower cell densities, however, Cav-1 inhibits the Sprouty function [101]. Moreover, Hwangpo et al. indicated the interaction between Spry 2 and G protein $\alpha_{\mathrm{o}} / \mathrm{G}$ proteinregulated inducer of neurite outgrowth $\left(\mathrm{G} \alpha_{\mathrm{o}} / \mathrm{GRIN}\right)$ pathway in modulating Spry2 repression of ERK [102]. Although GRIN was shown to bind and sequester Spry2, the activated $G \alpha_{o}$ interacted with GRIN to release Spry2.

Sprouty phosphorylation on the conserved tyrosine is considered as an indispensible prerequisite for the regulatory function of Spry1 and Spry2 [99, 103], but not for that of Spry4 $[72,76,89]$. This process, however, is variably induced by different growth factors. Using NIH3T3 fibroblasts transfected with Spry1, Spry2 and Spry4 [89], Mason et al. observed that Spry1, Spry2, but not Spry4 undergo tyrosine phosphorylation after growth factor stimulation. Moreover, although FGF induced tyrosine phosphorylation in both Spry 1 and Spry2, PDGF and EGF induced it in Spry1 and Spry2, respectively. Through a time course analysis, they also revealed that FGF-induced tyrosine phosphorylation of Spry1 is kinetically different from that of Spry2. In agreement with earlier reports [87, 103], the investigators found that tyrosine phosphorylation regulates interaction of Sprouty with c-Cbl and concluded that tyrosine phosphorylation serves as a dual feedback loop which, on the one hand, activates Sprouty inhibition of ERK and, on the other hand, promotes c-Cblmediated ubiquitination and degradation of Sprouty and thus terminates signaling inhibition. Functional significance of Sprouty phosphorylation on other residues than the conserved tyrosine has also been studied. Rubin et al. [104] observed in HEK293T cells that FGF, but not EGF, activation of ERK is inhibited by Spry2 and that only FGF can induce significant phosphorylation of the C-terminal tyrosines, in particular Tyr227. On this basis, they postulated that $\mathrm{C}$-terminal tyrosine phosphorylation modulates the specificity of the Spry2 inhibition of different ERKs. Results from a study by Aranda et al. supported a functional interaction between dual-specificity tyrosine phosphorylation-regulated kinase 1A (DYRK1A) and Spry2 where DYRK1A regulates the phosphorylation status of Spry2. Since mutation of Thr75 on Spry2, identified as a phosphorylation site for DYRK1A, enhanced the repressive function of Spry2 on FGF-induced ERK signaling, they suggested that DYRK1A is a negative regulator of the Sprouty activity by threonine phosphorylation.

Sprouty dephosphorylation by phosphatases, including protein phosphatase 2A (PP2A) and Src homology-2 containing phosphotyrosine phosphatase (SHP2), can differentially regulate the protein activity. In unstimulated cells, Sprouty is phosphorylated predominantly on serine residues [6]. Lao et al. found that PP2A binds and dephosphorylates Spry2 at Ser112 and Ser115 upon FGF stimulation [105]. They postulated that Spry2 serine dephosphorylation alters the tertiary structure of the protein and thereby exposes the cryptic proline-rich motif in the Spry2 C-terminus, which they had earlier identified as a binding site for Grb2 [106], enabling Spry2 to potently inhibit FGF activation of ERK. They also found that PP2A and c-Cbl compete for binding to Spry2 at an overlapping sequence to fine-tune its activity. They later reported that testicular protein kinase 1 (TESK1) attenuates the ability of Spry2 to inhibit the growth factor actions in a way independent of its kinase activity and primarily by interfering with Spry2/Grb2 interactions and dephosphorylation of serine residues by PP2A [107]. SHP2 has been implicated in regulating the Sprouty activity through dephosphorylation of the phosphotyrosines and subsequent dissociation of Sprouty from Grb2 that positively regulates growth factor activation of ERK [57, 108, 109]. Pan et al. showed that SHP2 regulates Sprouty positively at the transcriptional level and negatively at the post-translational level and concluded that dynamic regulation of Sprouty by SHP2 might be important not only for modulating Ras signaling in developmental processes, but also for RTK signaling in general [37]. On the other hand, Sprouty may mediate its actions in part by increasing active contents of such phosphatases as protein tyrosine phosphatase 1B (PTP1B) and phosphatase and tensin homolog (PTEN). Regulating subcellular localization of PTP1B, Sprouty increases PTP1B soluble content which has been shown to mediate, and mimic, Sprouty-induced repression of cell adhesion and migration [35, 62]. Poppleton et al. reported that Sprouty, regulates cell migration by inhibiting Racl activation which they postulated, is mediated in part by PTP1B dephosphorylation of cellular proteins and, subsequently, decreased the amount of phosphorylated p130Cas or phosphatidylinositol 3,4,5-trisphosphate (PIP3) known as Rac1 activators [46]. In a study by Edwin et al. [64], where Spry2 unexpectedly inhibited EGF activation of AKT and exhibited no significant effect on EGF activation of EGFR and ERK, they observed that Spry2 increases the amount and activity of PTEN that was found necessary for Sprouty to attenuate EGF-activated AKT and to inhibit cell proliferation. Beyond its cytoplasmic role in negatively regulating PI3K/AKT, PTEN is phosphorylated and accumulated in the nucleus in response to the Spry2 deficiency to induce p53-mediated growth arrest independently of its phosphatase activity [110]. This process is part of a regulatory mechanism involving Spry2 interaction with PP2A and PTEN for inhibition of tumorigenesis which will be discussed later.

\subsection{Regulation of RTK activity and stability}

Sprouty might regulate activity and stability of RTKs through interaction with mechanisms involved in reversible (transient) 
and irreversible (definitive) inhibition of ERK on the basis of dephosphorylation (inactivation) and degradation (downregulation) of RTKs, respectively. Among the reversible inhibitory mechanisms is the RTK dephosphorylation by PTP1B that provides spatiotemporal regulation of the RTK activity [111]. Despite the fact that PTP1B, as described earlier, is regulated by Sprouty to control some cellular functions on the basis of protein tyrosine phosphorylation, there is no evidence of direct interaction between Sprouty and PTP1B in RTK dephosphorylation. In contrast, it is well documented that Sprouty interferes with c-Cbl-mediated downregulation of RTK in a growth factor-dependent manner. Sprouty evidently inhibits c-Cbl-induced ubiquitination and degradation of EGFR, thereby sustaining EGF-activated ERK [7, 87, 103, 112, 113]. Rubin et al. [88] postulated that EGFR activation, followed by Spry2 phosphorylation and its association with c$\mathrm{Cbl}$, initiates a competitive process where c-Cbl promotes Spry2 polyubiquitination and degradation, and Spry2, conversely, sequesters active c-Cbl molecules and impedes receptor ubiquitination and degradation. They concluded that Sprouty fine-tunes EGF signaling through interlinked positive and negative feedback loops. Moreover, Edwin and Patel [65] suggested a novel role for Sprouty in regulating cellular apoptosis where endogenous Sprouty, by sequestering c-Cbl, augments EGFR activation of ERK and AKT pathways and the resultant anti-apoptotic signaling. A c-Cbl-independent mechanism for Sprouty-induced upregulation of EGFR was identified by Kim et al. [114]. They reported that Spry2 interferes with the trafficking of activated EGFR from early to late endosomes. To do so, Spry2 was postulated to bind the endocytic regulatory protein hepatocyte growth factorregulated tyrosine kinase substrate (Hrs) to prevent it from interaction with the tumor susceptibility gene 101 protein (Tsg101) which is required for EGFR transport.

\subsection{Structural variation and functional divergence of the Sprouty proteins}

The C-terminal cysteine-rich (CRD) domain of Sprouty is a highly conserved region implicated for such key functions of the protein as a membrane translocation and ERK inhibition $[61,87,98$,$] . The N-terminal tyrosines Tyr53 (in Spry1 and$ Spry4) and Tyr55 (in Spry2) are also conserved residues crucial for the Sprouty functionality to the extent that their corresponding dominant-negative mutants fail to attenuate ERK signaling and even repress the function of the wild type (WT) protein [60, 72, 76, 89, 99]. Less homologous sequences, however, have been localized in the C-terminal as well as in the N-terminal regions of the Sprouty isoforms that contribute to their differential interaction with signaling molecules and molecular partners and accounts, in part, for their functional divergence. Sprouty isoforms display differential affinity for different molecular targets upstream or downstream of Ras or even beyond ERK. Although interacting with Raf kinases [115-118], Spry2 exhibits the highest affinity for Grb2. Lao et al. identified an exclusive proline-rich sequence in the Spry2 C-terminus which was found as a binding site for Grb2 responsible for differential interaction of Spry2, as compared to Spry1 and Spry4, with Grb2 [106]. Sasaki et al. [76] demonstrated that the Spry4 mutants lacking the N-terminal conserved tyrosine residue necessary for suppressing FGF signaling still inhibit the VEGF-A-induced activation of ERK in a Ras-independent manner by binding through the CRD domain to Rafl, indicating that Spry4 differentially regulates different ERK pathways through distinct action points. Later, in a study by Ayada et al. [119], the CRD domain was further implicated for the Spry4 functions in regulating the VEGF-A-induced, protein kinase C- (PKC-) dependent activation of ERK, as well as various types of PLC-dependent signaling. The investigators indicated that Spry4 interacts through its CRD domain with PIP2 to inhibit PIP2 hydrolysis and ensuing activation of PKC in response to VEGF-A. Also found to impact the PKC downstream signals, Spry4 was introduced as a general inhibitor of phospholipase C (PLC) and PLC-dependent signaling with regulatory functions broader than previously thought [119]. In a parallel study, investigating the physiological function of Spry4 as an angiogenic regulator [120], they indicated that Spry4 suppresses Ras-independent angiogenesis stimulated by VEGF-A and sphingosine-1-phosphate (S1P) while it does not affect Ras-dependent VEGF-C signaling. TESK1, a cofilin kinase with critical role in integrin-mediated actin cytoskeletal reorganization and cell spreading, was identified by Tsumura et al. [49] as a target for the Spry4 CRD domain through which Spry4 binds TESK1 and inhibits cofilin phosphorylation, thereby negatively regulating cell spreading and migration independently of its regulatory effect on ERK.

Variation in the binding sites for such molecular partners as c-Cbl, CIN85, and Cav-1 is also documented. Known to mediate monoubiquitination of activated RTKs [121-123], c-Cbl interacts with endocytic scaffold complexes, including CIN85/endophilins, to facilitate RTK endocytosis and degradation [124-126]. The N-terminal c-Cbl binding motif is shared by Sprouty isoforms. However, Spry2 exhibits the highest binding affinity for c-Cbl and Spry 4 weakly binds it $[113,127]$. Mason et al. [89] found that tyrosine phosphorylation is essential for Sprouty association with c-Cbl and that a less homologous sequence within the c-Cbl binding motif of Spry4 prevents it from phosphorylation and binding to c-Cbl. Furthermore, principal CIN85-binding sites are found only in Spry1 and Spry2. Haglund et al. showed that Spry2 associates with c-Cbl and CIN85 upon EGF stimulation to inhibit EGFR endocytosis and degradation, whereas Spry4 fails to inhibit downregulation of EGFR [128]. Sprouty isoforms have also shown differential interaction with Cav-1. Cabrita et al. showed that although all four Sprouty isoforms can bind 
Cav-1 through their conserved C-terminal domain, they exhibit differential cooperativity with Cav-1 in repressing ERK [101]. When either Spry1 or Spry3 were expressed in the presence of Cav-1, FGF-induced ERK activation was synergistically attenuated. However, when either Spry2 or Spry4 were present along with Cav-1, ERK activation increased slightly compared with when Cav-1 was present by itself, suggesting a decrease in the inhibitory activity of Cav-1. In addition, it was shown in another study that inhibitory function of the Sprouty proteins is enhanced through cooperative interaction among the protein isoforms. Ozaki et al. [129] found that all four Sprouty isoforms are able to form heteroand homo-oligomers through their C-terminal domains. They observed that while Spry1 and Spry4 interact with Grb2 and Sos1, respectively, the hetero-oligomer formed by the two exhibits the most potent inhibitory effect on FGF-activated ERK.

\section{Deregulation of Sprouty in cancer}

Given their critical role as modulators of MAPK/ERK and mediators of the crosstalk between ERK and other signaling pathways for maintaining homeostatic control of cellular behavior, the Sprouty proteins are conceivably expected to be deregulated in malignant conditions. On this basis, deregulation of Sprouty in a variety of cancers has been studied by different investigators and its utility as a biological marker [21, 69, 110, 130-134 ], a tumor suppressor [41, 52, 66, 135-140], or even an oncogene [55, 68-70, 141, 142] with application in targeted approaches $[13,52,56,69,131,134$, $143,144]$ has been argued which are discussed below.

\subsection{Breast cancer}

In a study by Lo et al. in 2004, although mSpry1 and mSpry2 were implicated in the breast development during puberty and pregnancy [21], it was revealed in Cancer Profiling Array containing pairs of complementary DNAs (cDNAs) generated from 50 matched pairs of normal and cancer tissues that hSpryl and hSpry 2 were consistently downregulated in breast cancer. Real-time PCR confirmed that more than $90 \%$ of the patient samples demonstrated suppressed expression of Spry 1 and Spry2. Neither DNA methylation nor histone hypoacetylation was found to be responsible for the Sprouty downregulation by an epigenetic silencing. They finally indicated that the MCF-7 breast cancer cells transfected with a dominant-negative mutant of Spry 2 proliferated faster and exhibited anchorage-independent growth in vitro and formed larger tumors in vivo. Following a meta-analysis of the gene expression profiles of a total of 1,107 tumors combined with a further analysis of two single datasets, Faratian et al. [132] reported in 2011 that Spry1, Spry2, and Spry4 were differentially expressed across clinicopathological subgroups of the breast cancer and that low Spry2 expression was associated with high expression of the human epidermal growth factor receptor 2 gene (HER2). Spry2 was found as an independent prognostic factor that may identify breast cancer patients with a more favorable outcome even when tumors exhibit poor pathological features. Since Spry2 was shown to act synergistically with the HRE2-targeting trastuzumab to reduce cell viability in vitro, the expression of Spry2 was quantified in a cohort of 122 trastuzumab-treated patients, revealing that low Spry2 expression was associated with poor outcome and increased risk of death. Hence, the investigators argued for the usefulness of Spry 2 in stratifying patients for treatment with trastuzumab.

Implicating the urokinase-type plasminogen activator receptor (UPAR) as a partner protein interacting with hSpryl [145], Mekkawy et al. reported that hSpry1 colocalizes with uPAR upon stimulation with EGF and urokinase-type plasminogen activator (UPA), and suppresses uPAR-mediated migration and invasion of the MDA-MB-231 breast cancer cells [59]. Vanas et al. [146] recently indicated that different breast cancer cell lines differentially express Sprouty as compared with normal mammary epithelial cells. However, a correlation between the expression profiles of Spry2 and Spry4 was found. They also reported that ectopic expression of Spry4 inhibited cell proliferation independently of its endogenous expression level. Furthermore, increased Spry4 interfered with serum-induced activation of ERK and inhibited cell migration.

\subsection{Prostate cancer}

In 2004, Kwabi-Adoo et al. [143] reported the result of immunohistochemical analysis of 407 tissue microarrays containing prostate cancer, as well as matched normal tissue cores, showing downregulation of hSpryl in approximately $40 \%$ of the prostate cancer cases studied. This finding was corroborated by real-time PCR where Spry1 mRNA levels were significantly decreased in 16 out of 20 prostate cancer tissue samples in comparison with the normal tissue. In their in vitro study, the investigators interestingly observed that the prostate cancer cells LNCaP and PC3, in contrast to primary epithelial cells, did not show induction of the Spry1 expression at mRNA and protein levels in response to FGF2 stimulation. They also reported that Spry1 transfection of LNCaP and PC3 cells had an inhibitory effect on colony formation and cell proliferation. In agreement with earlier studies showing upregulation of FGFs in prostate cancer, Kwabi-Adoo et al. concluded that Spry1 downregulation may lead to the unrestrained FGF-induced signal transduction and hence tumor progression. Later, McKie et al. [135] observed that Spry 2 mRNA is downregulated in invasive prostate cancer cell lines as well as in clinically high-grade prostate cancers 
when compared to benign prostatic hyperplasia (BPH) and well-differentiated prostate tumors. Identifying hypermethylated $\mathrm{CpG}$ islands in $h$ Spry 2 gene correlated with suppressed expression of hSpry 2 mRNA, they implicated epigenetic inactivation as the main mechanism for the $h$ Spry 2 downregulation in prostate cancer. As later reported by Kwabi-Adoo et al., this mechanism is also responsible for downregulation of Spryl in prostate cancer [147]. Data from an integrated genomic profiling of 218 prostate tumors by Taylor et al. revealed that Spryl and Spry2 genes are inactivated in 15 and $18 \%$ of the primary cancer, as well as in 42 and $74 \%$ of the metastatic disease, respectively [148]. Through in situ hybridization on 14 prostate tissue samples and quantitative real-time PCR analysis in 25 pairs of matched normal and tumor tissue samples, downregulation of Spry 4 in a subset of prostate cancers was reported by Wang et al. [51]. Their epigenetic analysis revealed methylation of a $\mathrm{CpG}$ island in the 5'-regulatory region of Spry4 in more than a half of all prostate cancer DNA samples studied which was significantly correlated with decreased expression of Spry4 mRNA. They also demonstrated that Spry4, unlike Spry1, does not hinder cell growth but rather inhibits cell migration, suggesting that Spry1 and Spry4 perform different functions in prostate cancer. Later, Fritzsche et al. [149] observed through microarray analysis of microdissected prostate tissue specimens a coordinated, yet modest, downregulation of both Spry1 and Spry2 mRNAs gradually increasing from hyperplasia to severe prostatic intraepithelial neoplasia (PIN) to cancer. Spry 2 mRNA downregulation was confirmed in an independent, larger series of macrodissected tumors by quantitative RT-PCR. Unlike McKie et al., however, they reported that Spry2 downregulation in prostate cancer is independent of DNA methylation.

ERK and PI3K/AKT have been identified as the two most commonly altered pathways in prostate cancer with alteration frequency of $42-43 \%$ in primary and $90-100 \%$ in metastatic prostate cancer [148]. Activation of ERK and PI3K/AKT by aberrant RTK signaling has been implicated in the development of aggressive prostate cancer [150]. On this basis, Sprouty interactions with other feedback regulators of the two pathways and its significance in prostate cancer tumorigenesis and progression have been explored by some investigators. PTEN has been reported to be inactivated in $4 \%$ of the primary prostate cancer as well as in $42 \%$ of the metastatic disease [148]. A key genetic interaction between the Sprouty and PTEN genes has been reported. Although Pten heterozygosity per se results in low-grade PIN in mice [151], Schutzman et al. [140] showed that concomitant inactivation of the Sprouty genes (Spryl and Spry2) accelerated emergence of PIN and promoted development of more extensive, high-grade phenotype along with the transition to invasive cancer. Conversely, expression of a Spry2 gain-of-function transgene in the context of Pten homozygosity suppressed the AKT hyperactivation, and the prostate tumorigenesis resulted from Pten loss-of-function, implicating the Sprouty genes in regulation of ERK and PI3K/AKT pathways in prostate cancer. They suggested that the expression status of the PTEN and Sprouty genes in prostate biopsies from men at risk for prostate cancer could potentially help to riskstratify patients with PIN. Patel et al. later indicated that Sprouty status along with that of PTEN and PP2A collectively represents an important determinant of the prostate cancer progression [110]. They showed in a coherent set of in vitro and in vivo systems that although Spry2 deficiency is sufficient to activate both PI3K/AKT and ERK cascades, it is insufficient to drive tumorigenesis with Spry2-deficient cells exhibiting PTENmediated growth arrest. As follows, it was shown that the Spry2 deficiency-induced growth arrest mechanistically involves PTEN, PP2A, glycogen synthase kinase 3 beta (GSK3B), p53, and reactive oxygen species (ROS). By enhancing RTK activation, Spry2 deficiency increases intracellular ROS which subsequently activates PP2A. PP2A then dephosphorylates and activates GSK3B that drives phosphorylation and nuclear accumulation of PTEN. Nuclear PTEN eventually promotes growth arrest by induction of $\mathrm{p} 53$ and $\mathrm{p} 21$, independent of its phosphatase activity. Overall, by introducing a novel, PP2A-dependent tumor suppressor checkpoint, Patel et al. identified the cooperative role of concomitantly inactivated Spry2, PTEN, and PP2A to drive the prostate cancer progression. Hence, they postulated that loss of Spry2 may represent an early event in prostate carcinogenesis compensated by nuclear PTEN-mediated growth arrest which might be subsequently overcome by inactivation of PTEN, TP53, or PP2A.

\subsection{Liver cancer}

In a gene expression study by Chen et al. in 2002, Spry2 was among the top 600 genes found to be differentially expressed in hepatocellular carcinoma (HCC) compared with non-tumor liver tissue [152]. In 2006, a more stringent and biologically relevant analytic approach to the same database by Fong et al. revealed a consistent downregulation of Spry2 in HCC [50]. Using in situ hybridization on tissue microarrays from an independent set of patients, they confirmed significantly differential expression of Spry2 in HCC compared with normal or cirrhotic liver tissue. Although showing the resemblance between the expression pattern of Spry2 and that of several potential tumor markers in hepatocellular carcinoma, the investigators ruled out loss of heterozygosity $(\mathrm{LOH})$ or the promoter hypermethylation as possible mechanisms responsible for Spry2 downregulation. Moreover, it was shown that Spry2 plays functionally important roles in HCC by inhibiting hepatocyte growth factor (HGF)-induced cell proliferation and ERK activation in the Spry2-overexpressing HCC cells.

Identifying Spry2 in their genomic analysis as a downregulated and frequently deleted gene in HCC, Lee et al. [66] 
observed in vitro that overexpressed Spry2 inhibits HCC cell growth. Their in vivo study using hydrodynamic transfection not only exhibited, in line with earlier studies [153, 154], the cooperative role of activated Wnt/ $\beta$-catenin and Ras in induction of HCC, but also revealed that dominant negative Spry2 cooperates with $\beta$-catenin to induce development of liver cancer in mice, with tumor cells showing upregulation of ERK and deregulation of genes involving in cell proliferation, apoptosis, and angiogenesis. This study suggested that Spry2 might function as a tumor suppressor in HCC. They reported later the synergistic role of Spry2 inactivation and c-Met upregulation in mouse and human hepatocarcinogenesis [155]. They observed in a collection of human liver tissue samples the significant downregulation of Spry2 protein as well as ubiquitously high expression of c-Met (total and activated) and its downstream effectors (activated Erk and $\mathrm{Akt}$ ) in most cases of $\mathrm{HCC}$ with poorer outcome (HCCP) in the context of WT Ras. The expression of Spry2 was found to be downregulated at transcriptional and post-translational levels by promoter hypermethylation, $\mathrm{LOH}$, and proteasomal degradation by NEDD4. In vitro, Spry2 overexpression inhibited c-Met-induced cell proliferation as well as ERK and AKT activation, whereas loss of Spry 2 potentiated cMet signaling. Their in vivo study with mice hydrodynamically transfected with c-Met and/or a dominant negative mutant form of Spry2 indicated that Spry2 inactivation cooperates with c-Met to induce hepatocarcinogenesis by sustaining proliferation and angiogenesis, suggesting a pivotal oncogenic mechanism responsible for unrestrained activation of ERK and AKT pathways in human hepatocarcinogenesis. By hydrodynamic injection and coexpression of an activated/ myristoylated form of Akt (myr-Akt) and a dominant negative Spry2 mutant in the mouse liver, Wang et al. [71] later indicated that loss of Spry2 accelerated AKT-induced hepatocarcinogenesis which was associated with activation of ERK pathway and pyruvate kinase M2 (PKM2)-induced glycolysis. In vitro, they found that activation of PKM2 in the HCC cell line HLE transfected with Akt and dominant negative Spry2 is independent of ERK and AKT cascades, collectively implying that loss of Spry2 synergizes with activated AKT to induce rapid hepatocarcinogenesis through the activation of ERK and PKM2 pathways.

Differential expression of the Sprouty homologs in HCC was reported by Sirivatanauksorn et al. [133], where paired HCC and non-tumor liver tissue samples from 31 patients were examined by quantitative RT-PCR. Most HCC tissues showed upregulation of Spry1 and downregulation of Spry2 and Spry4 at mRNA level. Moreover, mRNA expression of Spry1, Spry2, and Spry4 in cancerous specimens was significantly different from that in nontumor tissues. The expression of Spry3, however, did not show any significant difference among the samples. Studying the association of the Sprouty gene expression with clinical parameters of HCC, they indicated that the expression of Spry2 was significantly lower in patients with advanced disease and angiolymphatic invasion, whereas Spryl was significantly upregulated in cases without underlying cirrhosis compared with cirrhotic patients. Prognostic significance and clinical relevance of the Spry2 protein expression in HCC was later studied by Song et al. [134]. Their initial study in vitro showed that the ratio of phospho-ERK to Spry2 in the HCC cell lines MHCC97L, HCCLM3, and HCCLM6 displayed an elevation concordant with their stepwise metastatic potential. Similarly, the Spry2 expression per se inversely correlated with the metastatic potential of the HCC cells. In their immunohistochemical study, they found that $86.3 \%$ of a total of 240 patients exhibited Spry2 downregulation. They reported that Spry2 downregulation accompanied highly malignant clinicopathological features like advanced TNM stages and tumors with vascular invasion and poor differentiation. They found that Spry2-negative patients had poorer survival and increased postoperative recurrence, and thereby suggested potential implications of Spry2 as a predictor of the disease prognosis and a biomarker of the treatment sensitivity.

\subsection{Lung cancer}

Using reverse transcription-PCR and immunohistochemical staining of matched tumor and nontumor samples, Sutterluty et al. reported in 2007 that Spry2 expression, but not that of Spryl, is consistently reduced at mRNA and protein levels in non-small cell lung cancer (NSCLC) tissues [52]. Their in vitro analysis with a panel of NSCLC cell lines revealed that high levels of Spry2 expression were exclusively detected in KRAS-mutated cells and that only few cell lines with reduced Spry2 exhibited Spry2 promoter hypermethylation. Moreover, although ectopic expression of Spry2 inhibited ERK activity and diminished cell migration in NSCLC cells with WT KRAS, but not in those with the mutated one, it significantly reduced cell proliferation in all NSCLC cell lines studied in vitro and blocked tumor formation in mice inoculated with the KRAS-mutated cell line A-549. In addition, even a dominant negative Spry2 mutant defective in antagonizing ERK significantly, although less potently, inhibited cell proliferation in NSCLC cells with or without KRAS mutation. Collectively, they demonstrated that Spry2 downregulation contributes to NSCLC tumorigenesis via ERK-dependent and ERKindependent mechanisms and implicated Spry2 as a tumor suppressor in NSCLC. Consistently, Shaw et al. reported that Spry2 functions as a tumor suppressor in the context of a germline oncogenic KRAS mutation-KRAS ${ }^{\mathrm{G} 12 \mathrm{D}}$ - in which loss of Spry2 increased the number and overall burden of lung tumors in mice [31]. This was corroborated by a later report whereby lack of Spry2 expression along with high level of ERK activation was evident in putative tumorigenic cells of $\mathrm{KRAS}^{\mathrm{G} 12 \mathrm{D}}$-induced neoplasia in mouse lungs [156]. The role 
of Spry2 in inhibiting lung tumor development was further confirmed by Minowada et al. [144] who evaluated consequences of Spry2 overexpression in mouse lung epithelium in the context of urethane-induced tumorigenesis. The chemical carcinogen urethane induces KRAS gain-of-function mutations and lung tumors in mice. The investigators observed that Spry2 overexpressing animals developed significantly fewer and smaller tumors compared with their littermate controls. Since the overexpression of Spry2 did not alter KRAS mutational frequencies, it was suggested that the tumorsuppressing activity of the overexpressed Spry 2 might be applied at stages of carcinogenesis subsequent to KRAS mutation.

A putative role for Spry4 as part of Wnt7A/Fzd9 tumorsuppressing pathway was initially suggested by Winn et al., where Wnt7A and Fzd9 induced the expression of Spry4 in NSCLC cells [136]. They subsequently identified PPAR $\gamma$ $[157,158]$ and Spry4 [56] as downstream effectors of Wnt7A/Fzd9 that mediate its anti-tumorigenic effects. Reporting downregulation of Spry4 in a variety of NSCLCs as well as in dysplastic lung cell lines, Tennis et al. showed that Spry4 transfection inhibited NSCLC cell growth, migration, invasion, and epithelial-mesenchymal transition. They found that Wnt7A/Fzd9 signaling increases Spry4 promoter activity through PPAR $\gamma$. Corroborated by their earlier reports $[158,157,136]$, Tennis et al. concluded that Spry4 represents an inducible effector of the Wnt7A/Fzd9 pathway downstream of PPAR $\gamma$ which restores a nontransformed epithelial phenotype while inhibiting NSCLC cell growth, migration, and invasion [56].

\subsection{Colon cancer}

In their cDNA array study on different cancers in 2004, Lo et al. presented differential expression pattern of Spry2 in 38 matched pairs of normal and tumor samples from colon cancer patients [21]. In a BLAST search of human ESTs followed by in silico expression analysis, Katoh and Katoh [13] observed that Spry 4 mRNA is expressed in colon cancer. Based on the comparative genomics analyses, they characterized Spry 4 as the evolutionarily conserved target gene of the $\mathrm{Wnt} / \beta$-catenin signaling pathway. Implicating Spry 4 in $\mathrm{Wnt} / \beta$-catenin regulation of progenitor cells, they suggested that epigenetic silencing and loss-of-function mutations of Spry4 could lead to carcinogenesis. In a study by Barbachano et al. [69], immunofluorescence analysis of human colon cancer biopsies quantitatively confirmed in 34 patients showed high levels of Spry2 and low levels of E-cadherin in undifferentiated, highgrade tumors in contrast to low levels of Spry2, and high levels of E-cadherin in low-grade specimens. In vitro, Spry2 and E-cadherin exhibited an inverse correlation and reciprocal regulation in colon cancer cells. The investigators found that Spry2 induces the expression of the ZEB1 epithelial-to- mesenchymal transition gene and protein and abrogates the induction of an adhesive epithelial phenotype by $1,25(\mathrm{OH}) 2 \mathrm{D} 3$. Supplemented by a meta-analysis of the data available at the Oncomine database [159] in favor of higher expression of Spry2 in colon tumors compared with other neoplasias, their results suggested a tumorigenic action and a potential role as a tumor marker for Spry2 in colon cancer. Examining a low number of matched colon cancer samples, Holgren et al. [68] also reported upregulation of Spry2, as well as c-Met, at mRNA and protein levels. In vitro, Spry2 upregulation in the KRAS-mutated cell line HCT-116 significantly increased cell proliferation, accelerated cell cycle transition and enhanced cell migration and invasion which were attributed, at least in part, to activation of HGF/c-Met axis and its downstream effectors Akt and Erk. They also demonstrated that Spry-2 knockdown significantly inhibited cell invasion in both WT- and mutant KRAS-expressing cell lines. With Spry2 transfectants forming significantly larger xenografts with higher metastatic potential in vivo, they concluded that Spry2 may control metastatic potential of colon cancer cells, at least in part, by c-Met upregulation. Examining primary tumor samples from 113 patients with colorectal cancer, Watanabe et al. [160] later observed that KRAS mutant tumors (31\%) exhibited a distinct gene expression signature compared with their WT counterparts (69\%) where Spry2 was among the 30 genes upregulated in the KRAS mutants. They found that the discriminating genes identified were related to not only $\mathrm{K}$ Ras/ERK but other signaling pathways such as Wnt/ $\beta$ catenin, NF-kappa B activation, and TGF $\beta$ signaling, thereby suggesting a crosstalk between K-Ras-mediated signaling and other pathways in colorectal cancer.

In contrast, Feng et al. reported in 2010 that Spry 2 may be a potential biomarker in predicting the response to anti-EGFR treatment in colon cancer [131]. They showed that the expression of Spry2 positively correlates with the sensitivity of colon cancer cells to the EGFR inhibitor gefitinib and that Spry2 can enhance the response of colon cancer cells to gefitinib by increasing the expression of phosphorylated EGFR, total EGFR, and PTEN. They later reported downregulation of Spry2 in association with colon cancer progression and suggested a tumor suppressor role for Spry2 [137]. By real-time quantitative RT-PCR on mRNA isolated from normal and tumor tissues of 67 patients with colon cancer, they showed that Spry2 was downregulated in $72.7 \%(16 / 22)$ of stage II, $91.3 \%(21 / 23)$ of stage III, and $100 \%(22 / 22)$ of stage IV tumors examined. A negative correlation was also evident between the expression levels of Spry2 and the microRNA miR-21, an indicator of poor survival and poor response to adjuvant chemotherapy in cancer patients. In vitro, overexpressed Spry2 inhibited the growth and migration of HCT116 human colon cancer cells which was concomitantly accompanied by an increase in the expression of PTEN and reduction in phosphorylation of ERK and Akt. Spry2 also 
suppressed the growth and tumorigenesis of colon cancer cells in vivo. In line with earlier studies suggesting Sprouty genes as targets of miR-21 [161-163], they proposed that Spry2 is negatively regulated by miR-2 1 and that such interaction may play a role in colon cancer carcinogenesis. Spry1, too, was later found to inhibit EGF- or uPA-induced migration of HCT116 cells in vitro [59].

\subsection{Melanoma}

Examining a panel of melanocytic and melanoma cell lines, Tsavachidou et al. reported in 2004 that Spry2 acts as an inhibitor of ERK signaling in melanocytes and WT BRAF melanoma cells, but not in cell lines with $\mathrm{BRAF}^{\mathrm{V} 600 \mathrm{E}}$ (previously designated as $\mathrm{BRAF}^{\mathrm{V} 599 \mathrm{E}}$ ) mutation [117]. Their genetic and gene expression analyses revealed that Spry2 is downregulated in melanoma cells harboring WT BRAF yet upregulated in the BRAF ${ }^{\mathrm{V} 600 \mathrm{E}}$ mutants. They observed that Spry2 directly interacted with WT B-Raf and inhibited ERK but failed to directly bind the mutant B-Raf and did not affect ERK. In conclusion, they proposed that Spry2 may be bypassed in melanoma cells either by downregulation of its expression in WT BRAF cells or through BRAF mutation. In a later study [164], microarray data validated by real-time PCR indicated upregulation of Spry2 in melanoma cell lines with mutations in BRAF and NRAS. Qi et al. [95] showed that the expression of a dominant-negative Siah2 RING finger mutant in SW1 mouse melanoma cells reduced their tumorigenesis through the increase of Spry2. Using genomic and gene expression analyses of an animal model of skin neoplasm that produces both benign and malignant tumors, Quigley et al. [165] demonstrated that alleles that are not relevant in normal tissue are associated with tumor susceptibility but somatic alterations during tumor progression may reduce the detectable influence of germline polymorphisms. As such, although Spry2 was identified as a susceptibility gene for skin tumors and was expressed at very low levels in normal skin and at elevated levels in tumors, higher Spry2 expression in tumors was found to be associated with greater resistance to tumorigenesis which was ascribed to the role of Spry2 in regulation of ERK. Through an integrative approach analyzing genomic and gene expression changes in relation to in vivo growth aggressiveness, Mathieu et al. [166] found that genomic loss of Spry1 and Spry2 - along with altered expression of some other genes - was associated with a more aggressive melanoma phenotype. However, no convincingly enhanced levels of ERK phosphorylation were found in the fast-growing subgroup of their melanoma model compared with its slow-growing counterpart. Given widespread activating mutations in BRAF and, in particular, inability of Spry2 to attenuate ERK in the context of $\mathrm{BRAF}^{\mathrm{V} 600 \mathrm{E}}$ mutation, their findings argue for a role of Sprouty in regulation of melanoma aggressiveness independent of attenuation of ERK.

\subsection{Sarcoma}

In 2005, gene expression profiling of 134 human sarcoma tumors by Baird et al. revealed upregulation of Spry2 in 2/7 of fibrosarcomas and $4 / 5$ of dermatofibrosarcomas [167]. Lito et al. reported upregulation of Spry2 protein in the human fibrosarcoma cell lines SHAC, HT1080, VIP:FT and NCI as well as in HRAS- and NRAS-transformed human fibroblasts [141]. They provided evidence that Spry2 is necessary for sarcoma formation by patient-derived fibrosarcoma cell lines or HRAS oncogene-transformed human fibroblasts through EGFR signaling. Indicating Spry2-dependent interaction of H-Ras with c-Cbl and CIN85, and the ability of Spry2 to sustain EGFR signaling and tumor formation in the context of HRAS activation, they indicated that the positive effect of Spry2 in sarcoma tumor formation by human fibroblasts is specific to HRAS transformation. Contrasting the role of Spry2 in HRAS transformation with that earlier reported in $\mathrm{KRAS}^{\mathrm{G} 12 \mathrm{D}}$ mutation [31], Lito et al. raised the possibility of the differences among oncogenic Ras isoforms in regulation of tumorigenesi resulted from Ras isoform-specific modes of action [141]. Using a similar model system, they later showed that oncogenic HRAS requires Spry2 to protect fibroblasts from UV-induced apoptosis and damage and to resist cisplatin cytotoxicity. This antiapoptotic function of Spry2 was found to be mediated by a pathway consisting of Akt, human double minute 2 (HDM2), and p53 recruited through Rac1 [55]. In another study, gene expression profiling by Schaaf et al. [70] revealed that Spryl and Spry2, and Spry4 were consistently upregulated in the embryonic subtype of rhabdomyosarcoma (ERMS) as compared with its alveolar subtype (ARMS). They indicated that elevated Spry1 in ERMS cells associated with hyperactive ERK signaling is caused by oncogenic RAS mutations which is frequent in ERMS but absent in ARMS. Spry1 was found essential for ERMS cell proliferation and survival in vitro and ERMS tumor formation and maintenance in vivo. Accordingly, silencing of Spry 1 abolished tumorigenicity of ERMS cells and caused regression of established ERMS tumors in mice. Thus, they argued that Spry1 functions as an agonist of ERK signaling in rhabdomyosarcoma with RAS mutation.

A microarray analysis of 41 soft tissue tumors reported by Nielsen et al. in 2002 [168] revealed that Spry1, Spry4, and $K I T$ were among the genes that demonstrated specific expression in gastrointestinal stromal tumors (GISTs). Using expression profiling of the GIST882 cells treated with the c-Kit inhibitor imatinib in vitro, Frolov et al. later identified Spry4 as an imatinib-responsive gene significantly downregulated in the treated cells and the Spry4 protein as a downstream effector of the c-Kit-activated ERK targeted by the drug [130]. In their clinical study, since Spry4 levels were dramatically decreased in patients responsive to the drug compared 
with non-responsive patients, the authors proposed Spry4 as a reliable marker of the imatinib-responsive treatment.

Sprouty, on the other hand, has reportedly shown inhibitory effects on other types of sarcoma cells and tumors. Identifying Spry2 as an inducible, negative regulator of $\mathrm{HGF} / \mathrm{SF}$-induced activation of ERK and AKT, Lee et al. [63] reported in 2004 that Spry2 inhibits proliferation, anchorage-independent growth, migration, and invasion of SK-LMS-1 human leiomyosarcoma cells in vitro. Rathmanner et al. reported that Spry2, but not Spry4, potently inhibits proliferation and interfere with migration of human osteosarcoma-derived cells, with the N-terminal sequence variation being implicated in the specific inhibitory effect of Spry2 [169]. Osteosarcoma cell invasion was also shown to be impeded by overexpressed Spry1 as a result of interaction with uPAR [59]. A microarray study by Holtkamp et al. [170] identified Spry2 as one of the genes differentially upregulated in benign human neurofibroma as compared with malignant peripheral nerve sheath tumors (MPNST) from the same patient. Supporting a role for Sprouty in limiting the development of these benign lesions, Courtois-Cox et al. later reported that Sprouty genes were highly expressed in both Raf-expressing and neurofibromin 1 (NF1)-deficient fibroblasts [171]. They argued that Sprouty is part of a multifaceted negative feedback signaling network in response to the aberrant activation of Ras that underlies oncogene-induced senescence.

\subsection{B-cell lymphoma}

Reported in 2008, epigenetic silencing of hSpry2 and its clinical relevance in lymphoid/hematopoietic malignancies were investigated by Sanchez et al. [172]. Of 16 relevant human cancer cell lines, hSpry2 promoter was methylated only in the B-cell diffuse lymphoma cell line HT. This was found to be associated with and related to hSpry2 downregulation at mRNA and protein levels. The ectopic expression of hSpry2 in HT cells drastically reduced the phorbol 12myristate-13-acetate (PMA)-induced activation of ERK. The investigators then observed that HT mock cells developed tumors in nude mice seven times larger than those formed by the hSpry 2 transfectants. Clinically, they identified hSpry2 hypermethylation in 26 out of 71 patients with B-cell diffuse lymphoma as well as in 10 out of 13 Burkitt's lymphomas but in no normal B lymphocytes from 37 healthy individuals. As evaluated in 55 out of the initial 71 patients, the authors reported that Spry2 promoter hypermethylation was significantly associated with a lower 5-year survival rate and concluded that Spry 2 could be an important regulator in mouse Bcell diffuse lymphomas. In agreement, epigenetic silencing and repressed expression of Spry2 in mouse and human mature B-cell tumor cell lines and a T-cell leukemia 1-transgenic (TCL1-tg) mouse model of B-cell lymphoma as well as in human B-cell lymphoma samples were reported by Frank et al. [67]. Five out of seven diffuse large B-cell lymphomas and the only Burkitt's lymphoma sample studied contained DNA methylation of the Spry2 promoter which was associated with repressed Spry2 expression in 4 out of 6 lymphoma samples. Mechanistically, they demonstrated that Spry2 overexpression reduces ERK activation and induces B-cell apoptosis and Spry2 inactivation, on the other hand, increases ERK-dependent proliferation of B-cells. In conclusion, they implicated Spry2 in regulation of TCL1-augmented ERK signaling and B-cell proliferation and suggested Spry2 epigenetic silencing as an aberration contributing to B-cell lymphoma progression.

\subsection{Testicular germ cell cancer}

Results from a genome-wide scan among 277 cases of testicular germ cell tumors (TGCT) and a subsequent replication study on 371 cases were reported by Kanetsky et al. in 2009 [142] whereby genetic variation of KITLG (gene encoding the ligand for the receptor tyrosine kinase c-KIT) and Spry4 was shown to predispose to testicular germ cell cancer. These findings were found in agreement with an earlier report identifying Spry4 as downstream of c-KIT activation of ERK which is upregulated in GISTs in association with aberrant activation of c-KIT [130].

\subsection{Endometrial cancer}

Differential expression of Spry2 in normal endometrium throughout the menstrual cycle as well as in endometrial cancer was reported by Velasco et al. [41] in 2011. Indicating a complete absence of Spry 2 in about $20 \%$ of 136 cases immunohistochemically studied, they found that Stage III and IV tumors had the lowest levels of Spry2 immunostaining. Moreover, a strong, inverse correlation between the Spry2 expression and the cell proliferation index Ki67 was revealed, with nonendometrioid carcinomas (NEEC) exhibiting the highest level of cell proliferation and lowest level of the Spry2 expression. They concluded that Spry2 may be involved in regulation of endometrial carcinogenesis through control of cell proliferation.

\subsection{Thyroid cancer}

In 2012, Macia et al. [139] reported that Spry1 is expressed in mouse thyroid C-cells and that targeted deletion of Spryl causes C-cell hyperplasia, a precancerous lesion preceding medullary thyroid carcinoma (MTC), in young adult mice. They also found that ectopic expression of Spry1 in a tumorigenic, MTC-derived cell line reduced proliferation of the cancer cells in vitro and inhibited growth of the xenografts in vivo. Furthermore, they indicated that the Spryl promoter is frequently methylated and that the Spryl expression is 
accordingly decreased in human MTC samples, collectively suggesting that Spry1 is a candidate tumor-suppressor gene in MTC. By in vivo analysis of the thyroid glands from the Spry 1 knockout mice, they recently described a novel mechanism by which Spry1 induces a senescence-associated secretory phenotype via activation of the NF-kappaB pathway, thereby restricting cell proliferation independently of the ERK pathway [173].

\subsection{Pituitary tumor}

Investigating the role of the $\mathrm{C}$-terminal binding protein (CtBP), a transcriptional corepressor with known oncogenic properties, in normal and neoplastic pituitary, Dorman et al. [138] identified Spry2 as a potential target of CtBP1 and hence a potential tumor suppressor involved in regulation of pituitary cell growth and apoptosis. Gene expression profiling validated by real-time PCR and Western blotting revealed that Spry2 is upregulated in the CtBP1-deficient GH4 pituitary tumor cells that grow slower than their parental cells. Mechanistically, upregulation of Spry2 in CtBP1-deficient GH4 cell was shown to impair phosphorylation of the fibroblast growth factor receptor substrate 2 (FRS2 $\alpha$ ) in response to FGF.

\subsection{Ovarian cancer}

In a study by Polytarchou et al. [174], Spry1 was identified as a target of miR-21 in Akt2-conferred resistance to hypoxia in both normal and tumor cells. Upon oxygen deprivation, Akt2 was found to induce miR-21 which in turn targets and downregulates Spryl, PTEN, and programmed cell death 4 (PDCD4) led to enhanced survival of Akt2-expressing cells during hypoxia. They provided evidence that this hypoxiaactivated, Akt2-dependent pathway is present in ovarian cancer through examining a panel of ovarian cancer cell lines in vitro as well as real-time PCR analysis of 31 human ovarian cancer samples. In their initial report of an ongoing investigation into the role of Sprouty in ovarian cancer, MasoumiMoghaddam et al. later documented differential expression of Spry1 and Spry2 in a panel of ovarian cancer cells where a tendency for downregulation of Spry1 and/or Spry2 was evident [175].

\subsection{Clear cell renal cell carcinomas (ccRCC)}

In an attempt to identify genes effectively discriminating between clinically aggressive and nonaggressive ccRCC, Takahashi et al. performed the gene expression profiling of 29 tumors obtained from patients with diverse clinical outcomes. According to their report, Spryl was exclusively upregulated in the good outcome group [176].

In conclusion, the contributory role of the Sprouty downregulation in carcinogenesis and/or tumor progression and metastasis in the context of the breast [21], prostate [110, $135,140,147]$, liver [66, 71, 155], lung [31, 52, 56, 144, $157,158]$, colon [13, 137], melanoma [95, 165, 166], B-cell lymphoid [67, 172], and thyroid [139, 173] cancer is documented. This contribution is an apparent reflection of the critical role of Sprouty in regulation of cellular processes central to the development, progression, and dissemination of malignant conditions, including cell proliferation, migration, invasion, transformation, and survival (Table 2). Mechanistically, Sprouty regulates cell behavior through modulation of the ERK activation along with interaction with a wide range of players and ultimate involvement of other regulatory mechanisms and cellular pathways as depicted in Figs. 2 and 3. Nevertheless, context-dependent contribution of Sprouty to cancer tumorigenicity and metastatic potential has also been reported in colon cancer [68, 69], as well as in RAS mutated fibrosarcoma [141] and rhabdomyosarcoma [70] as a result of E-cadherin repression and ensuing inhibition of the adhesive epithelial phenotype [69], upregulation of c-Met [68], and a concomitant RAS mutation [70, 141].

\section{Sprouty in cancer: Complexity and controversy}

Under physiological conditions, as detailed earlier, Sproutymediated regulation is complex and multifaceted. Despite the initial understanding of Sprouty as a negative regulator of ERK, it is now evident that Sprouty has targets beyond ERK and functions, in concert with a variety of interacting molecules, in a cell- and context-dependent manner. Sprouty is differentially expressed by various normal cells not only during development, but also in adult organs in a tissue-specific or ubiquitous manner. Moreover, different Sprouty isoforms exhibit divergent regulatory functions. On this basis, it is not surprising that role of Sprouty in malignant conditions, where physiological homeostasis is altered in favor of neoplastic growth and progression, is fraught with intricacy and controversy. As discussed throughout this article, attempts have been made to shed light on unknown aspects of this story. In sum, our current knowledge indicates that the Sprouty's implication in cancer, similar to its role under normal circumstances, is cell type- and context-dependent. Although deregulation of the Sprouty genes can indicate a general aspect of the Sprouty status in a given cancer, this needs to be interpreted in relation to the gene expression at the protein level and pertinent functional outcomes. A rewired genetic network with the involvement of Sprouty and ERK signaling apparently promotes tumorigenesis. However, the Sprouty gene association with tumor susceptibility or resistance may not be necessarily associated with a consistent phenotype in vivo due to somatic alterations. Thus, a combination of genetic and gene expression analysis has been recommended to complement genetic association methods for identification of susceptibility or 


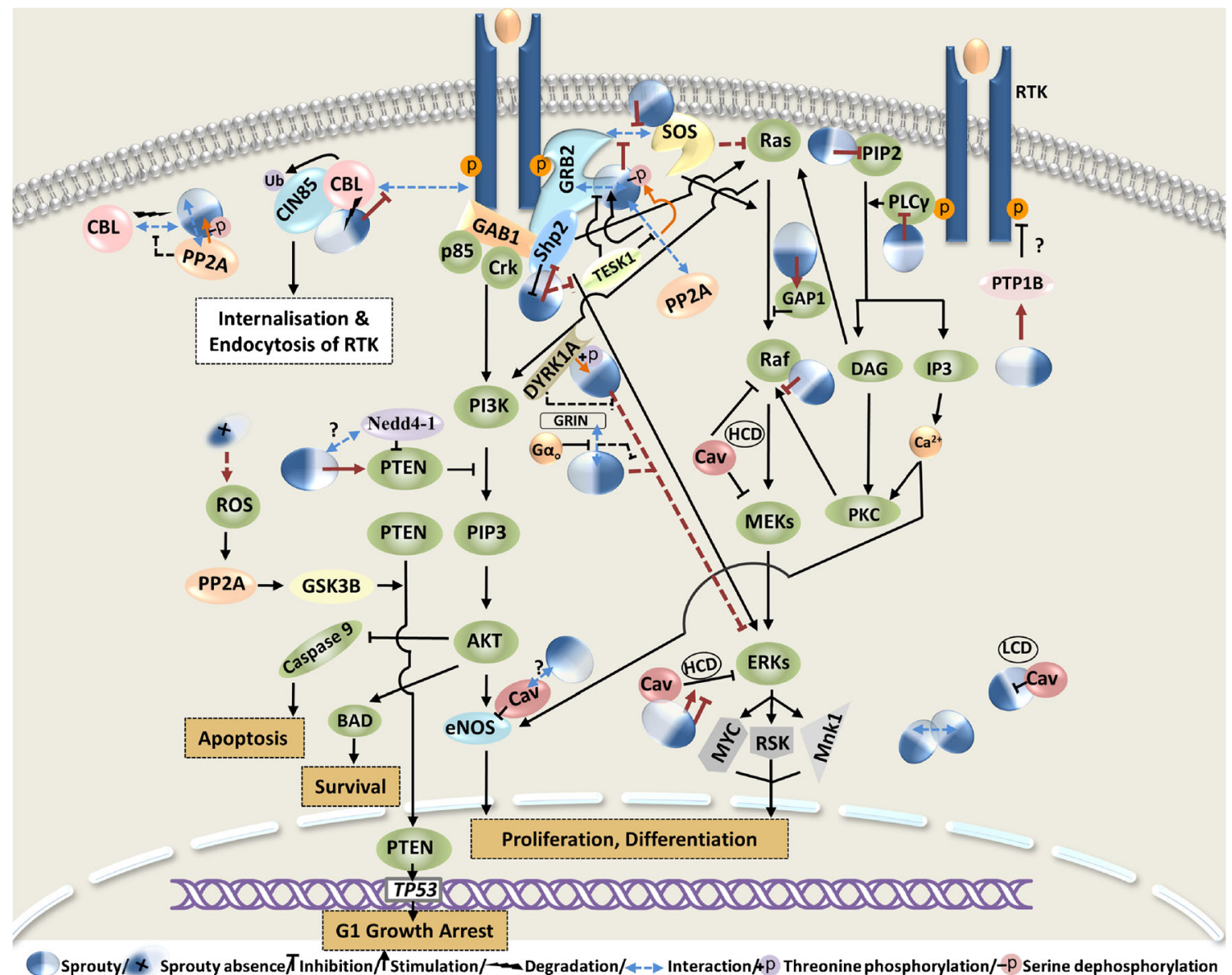

Fig. 2 Schematic illustration of the Sprouty-mediated regulation of cell proliferation, differentiation, and survival irrespective of the Sprouty isoform and cell type. Sprouty activity is resulted from or regulated through interaction with a number of players. This interaction impacts functionality of ERK and other signaling pathways. Sprouty binds $c-C b l$ and $C I N 85$ and sequestrate $\mathrm{c}-\mathrm{Cbl}$ to augment and prolong RTK signaling by inhibiting receptor endocytosis. This mechanism has been implicated in cell differentiation. E3 ubiquitin ligase c-Cbl, on the other hand, binds and induces degradation of Sprouty to restrict ERK activation. Sprouty has also been shown to interact with different phosphatases. It increases active contents of PTEN to mediate antiproliferative actions by inhibiting Akt activation. PTEN is also phosphorylated and accumulated in the nucleus in response to the Sprouty deficiency to induce p53-mediated growth arrest independently of its phosphatase activity. It is likely that the proto-oncogenic potential of NEDD4 is resulted in part from its ability to ubiquitinate both Sprouty and PTEN, resulting in unchecked activation of Akt. Sprouty also increases PTP1B content. However, there is no evidence of direct interaction between Sprouty and PTP1B in RTK dephosphorylation. Phosphatases $P P 2 A$ and SHP2 differentially regulate the Sprouty activity. Although PP2A potentiates Sprouty binding to Grb2 and thus positively regulates Sprouty by serine dephosphorylation, SHP2 promotes dissociation of Sprouty from Grb2 through tyrosine dephosphorylation and checks Sprouty inhibition of ERK. Moreover, interaction between Sprouty and kinases yields different outcomes. DYRK1A is considered a negative regulator of the Sprouty activity by threonine phosphorylation. TESK1 interferes with Sprouty/Grb2 interaction as well as with Sprouty serine dephosphorylation

resistance factors [165]. The expression of the Sprouty proteins, on the other hand, might be variably altered during tumorigenesis based on the pathogenic mechanism involved. by PP2A, thereby attenuating Sprouty functioning. Sprouty isoforms also exhibit differential cooperativity with $\mathrm{Cav}-1$ to repress growth factor activation of ERK. At low cell density, however, Cav-1 inhibits the Sprouty function. Sprouty is a general inhibitor of $P L C$-dependent signaling and inhibits various $P K C$ upstream and downstream signals, including PIP2 hydrolysis. Sprouty is an interacting partner of the $G \alpha_{o} / G R I N$ pathway. GRIN modulates Sprouty repression of ERK by binding and sequestering Sprouty. Activated $\mathrm{G} \alpha_{\mathrm{o}}$, on the other hand, promotes inhibition of ERK via interacting with GRIN and releasing Sprouty. Finally, interaction among the Sprouty isoforms is a mechanism through which oligomers with more potent activity can form. Cav Caveolin-1; $c$ - $C b l$ canonical Casitas B-lineage lymphoma; CIN85 Cbl-interacting protein of $85 \mathrm{kDa}$; DYRK1A dual-specificity tyrosine-phosphorylated and -regulated kinase $1 \mathrm{~A} ; G \alpha_{o} \mathrm{G}$ protein $\alpha_{\mathrm{o}} ;$ GRIN G protein-regulated inducer of neurite outgrowth; miR-21 microRNA 21; Mnk1 MAPK-interacting kinase 1; NEDD4 neural precursor cell expressed, developmentally down-regulated 4 ; $P A P C$ paraxial protocadherin; PIP2 phosphatidylinositol-4,5-bisphosphate; $P K C$ Protein kinase $\mathrm{C}$; $P L C$ phospholipase $\mathrm{C}$; $P P 2 A$ protein phosphatase $2 \mathrm{~A}$; $P T E N$ phosphatase and tensin homolog; $P T P 1 B$ protein tyrosine phosphatase 1B; $R T K$ receptor tyrosine kinase; SHP2 Src homology-2 containing phosphotyrosine phosphatase; Siah2 Seven in Absentia homolog 2; TESK1 testicular protein kinase $1 ; H C D$ high cell density; $L C D$ low cell density. In this figure, $\mathrm{C}$ - and $\mathrm{N}$-terminus of the Sprouty molecule symbol are shown in white and blue, respectively. Red lines indicate the Sprouty effect, with dashed lines representing indirect influence. Question marks refer to postulated, but not proven, interactions

Therefore, the expression pattern of Sprouty might be reflecting, for instance, a response to the mutant RASinduced hyperactivation of ERK or, on the contrary, the 


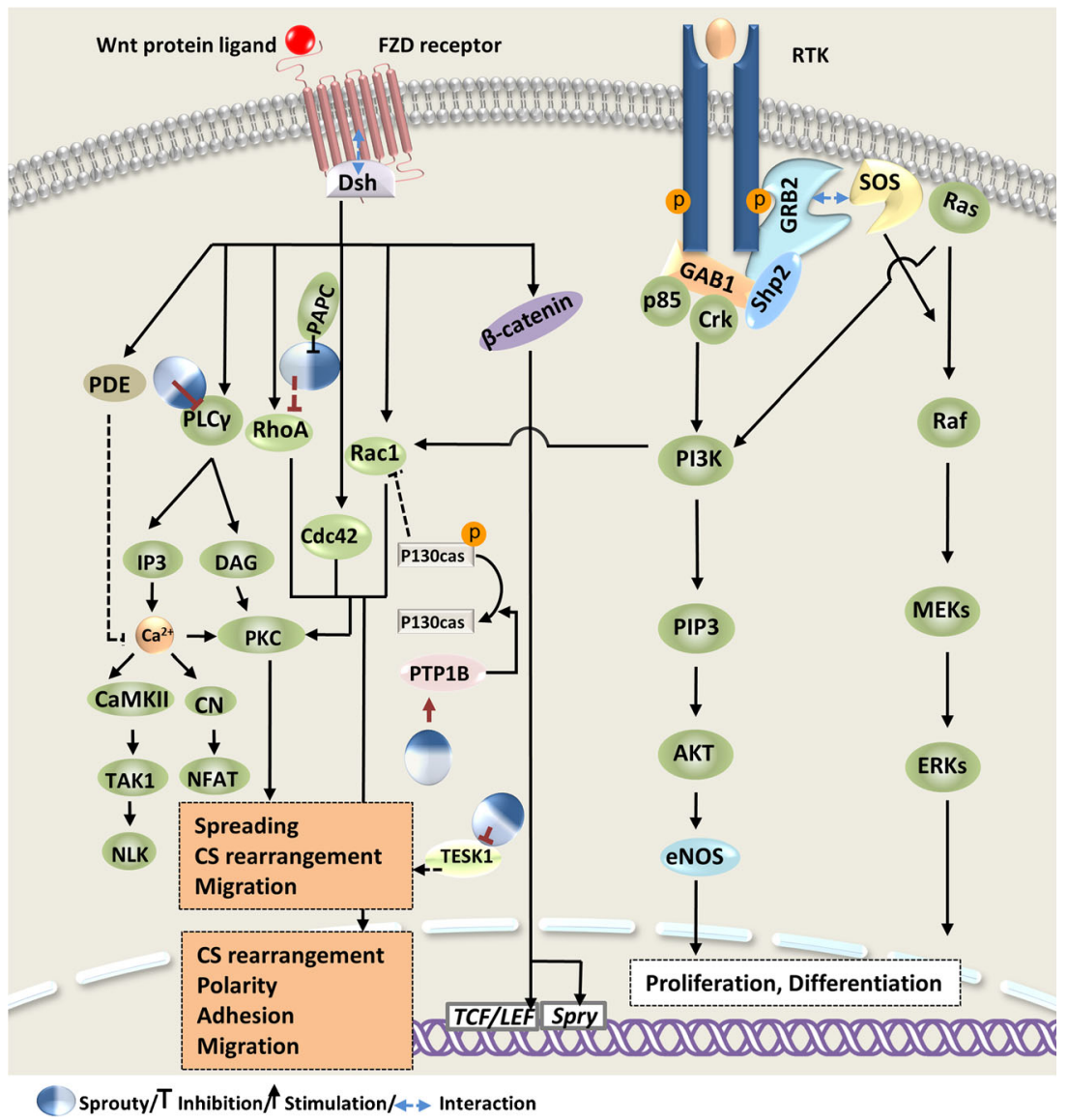

Fig. 3 Schematic illustration of the Sprouty-mediated regulation of cell migration, adhesion, and cytoskeletal rearrangement irrespective of the Sprouty isoform and cell type. Sprouty is shown to interact with phosphatases. It increases active contents of $P T P 1 B$ to mediate its antimigrative action by inhibiting activation of Rac1. Sprouty inhibits the kinase activity of TESK1 that plays a critical role in integrin-mediated actin cytoskeletal reorganization and cell spreading. Sprouty is a general inhibitor of $P L C$-dependent signaling and inhibits various $P K C$ upstream and downstream signals. Protocadherin $P A P C$ implicated in modulating beta-catenin-independent Wnt-signaling has been suggested to mediate its regulatory effect by binding and sequestering Sprouty. FZD receptor Frizzled receptor; $P A P C$ paraxial protocadherin; $P K C$ Protein kinase $\mathrm{C}$; $P L C$ phospholipase $\mathrm{C}$; $P T P 1 B$ protein tyrosine phosphatase $1 \mathrm{~B}$; $R T K$ receptor tyrosine kinase; TESK1 testicular protein kinase 1; CS rearrangement cytoskeletal rearrangement. In this figure, $\mathrm{C}$ - and $\mathrm{N}$ terminus of the Sprouty molecule symbol are shown in white and blue, respectively. Red lines indicate the Sprouty effect epigenetic silencing of the Sprouty promoter. Moreover, Sprouty's mode of action can be converted under malignant conditions. In the context of the RAS mutation, for example, Sprouty can function as an inhibitor $[31,52,171]$ or facilitator $[55,68,70,141$,$] of the tumor development and/or progres-$ sion. This might be resulted in part from different functionality of the RAS isoforms [141].

Collectively, the expression pattern of Sprouty in different types of cancer is just a reflection of the primary or secondary deregulations incurred under specific circumstances. Since Sprouty is physiologically able to function as both a repressor and an activator of RTK signaling, its specific implication needs to be individually investigated in different cancers where its mode of action be evaluated in relation to the malignant cell behavior. In this regard, although investigation of the Sprouty gene aberrations and relevant oncogenic mutations can provide clues to the underlying mechanisms, evaluation of the effect of the Sprouty expression on cancer cell biology along with analysis of the clinicopathological relevance of the Sprouty deregulation will yield a better understanding of the Sprouty biology in a given cancer with potential application in the Sprouty-based approaches.

\section{Conclusion}

Initially discovered as a growth factor antagonist with involvement in developmental processes, Sprouty is now recognized as a versatile modulator of ERK that also impacts other pathways to control crucial physiological processes in interaction with an increasing number of effectors, mediators, 
and regulators. Physiological functions of the Sprouty proteins are cell-specific and context-dependent. As such, Sprouty proteins are differentially induced in response to different growth factors and elicit divergent cellular responses. Moreover, transcriptional and post-translational regulation of the Sprouty content and activity provide spatiotemporal control of the Sprouty-mediated regulation. As regards the implication in malignancies, Sprouty has been the focus of research in a variety of studies for the past decade. Different patterns of the Sprouty deregulation have been reported in different cancers. As with normal cells, evidence shows that Sprouty in malignancies functions in a cancer cell-specific and contextdependent manner, hence its implication as a negative or positive regulator of the tumor progression. The presence of accompanying mutations of such oncogenes as RAS isoforms has also been shown to be an important determinant of the Sprouty's deregulation and mode of action. To evaluate the role of Sprouty in a particular cancer with respect to putative clinical applications, in-depth investigation of the Sprouty's expression and mode of action in relation to the malignant behavior of the cancer cell in the specific tumor microenvironment is warranted. This could give rise to a Sprouty-based stratification of individual patients where it serves as a biomarker of prognosis or treatment sensitivity as well as a focus of targeted strategies.

Conflict of interest The authors declare that they have no conflict of interest.

Open Access This article is distributed under the terms of the Creative Commons Attribution License which permits any use, distribution, and reproduction in any medium, provided the original author(s) and the source are credited.

\section{References}

1. Hacohen, N., Kramer, S., Sutherland, D., Hiromi, Y., \& Krasnow, M. A. (1998). Sprouty encodes a novel antagonist of FGF signaling that patterns apical branching of the Drosophila airways. Cell, 92(2), 253-263.

2. Kramer, S., Okabe, M., Hacohen, N., Krasnow, M. A., \& Hiromi, Y. (1999). Sprouty: a common antagonist of FGF and EGF signaling pathways in Drosophila. [Research Support, Non-U.S. Gov't Research Support, U.S. Gov't, P.H.S.]. Development, 126(11), 2515-2525.

3. de Maximy, A. A., Nakatake, Y., Moncada, S., Itoh, N., Thiery, J. P., \& Bellusci, S. (1999). Cloning and expression pattern of a mouse homologue of drosophila sprouty in the mouse embryo. [Research Support, Non-U.S. Gov't]. Mechanisms of Development, 81(1-2), 213-216.

4. Leeksma, O. C., Van Achterberg, T. A., Tsumura, Y., Toshima, J., Eldering, E., Kroes, W. G., et al. (2002). Human sprouty 4, a new ras antagonist on $5 \mathrm{q} 31$, interacts with the dual specificity kinase TESK1. European Journal of Biochemistry, 269(10), 2546-2556.

5. Gross, I., Bassit, B., Benezra, M., \& Licht, J. D. (2001). Mammalian sprouty proteins inhibit cell growth and differentiation by preventing ras activation. Journal of Biological Chemistry, 276(49), 46460-46468. doi:10.1074/jbc.M108234200.
6. Impagnatiello, M. A., Weitzer, S., Gannon, G., Compagni, A., Cotten, M., \& Christofori, G. (2001). Mammalian sprouty-1 and -2 are membrane-anchored phosphoprotein inhibitors of growth factor signaling in endothelial cells. Journal of Cell Biology, 152(5), 1087-1098.

7. Wong, E. S., Fong, C. W., Lim, J., Yusoff, P., Low, B. C., Langdon, W. Y., et al. (2002). Sprouty2 attenuates epidermal growth factor receptor ubiquitylation and endocytosis, and consequently enhances Ras/ERK signalling. EMBO Journal, 21(18), 4796-4808.

8. Gross, I., Armant, O., Benosman, S., de Aguilar, J. L., Freund, J. N., Kedinger, M., et al. (2007). Sprouty2 inhibits BDNF-induced signaling and modulates neuronal differentiation and survival. Cell Death and Differentiation, 14(10), 1802-1812. doi:10.1038/sj.cdd. 4402188.

9. Ishida, M., Ichihara, M., Mii, S., Jijiwa, M., Asai, N., Enomoto, A., et al. (2007). Sprouty2 regulates growth and differentiation of human neuroblastoma cells through RET tyrosine kinase. Cancer Science, 98(6), 815-821. doi:10.1111/j.1349-7006.2007.00457.x.

10. Minowada, G., Jarvis, L. A., Chi, C. L., Neubuser, A., Sun, X., Hacohen, N., et al. (1999). Vertebrate Sprouty genes are induced by FGF signaling and can cause chondrodysplasia when overexpressed. [Comparative Study Research Support, Non-U.S. Gov't Research Support, U.S. Gov't, Non-P.H.S. Research Support, U.S. Gov't, P.H.S.]. Development, 126(20), 4465-4475.

11. Ding, W., Bellusci, S., Shi, W., \& Warburton, D. (2004). Genomic structure and promoter characterization of the human Sprouty4 gene, a novel regulator of lung morphogenesis. [Research Support, Non-U.S. Gov't Research Support, U.S. Gov't, P.H.S.]. American Journal of Physiology - Lung Cellular and Molecular Physiology, 287(1), L52-L59. doi:10.1152/ajplung.00430.2003.

12. Tefft, J. D., Lee, M., Smith, S., Leinwand, M., Zhao, J., Bringas, P., Jr., et al. (1999). Conserved function of mSpry-2, a murine homolog of Drosophila sprouty, which negatively modulates respiratory organogenesis. [Research Support, U.S. Gov't, P.H.S.]. Current Biology, 9(4), 219-222.

13. Katoh, Y., \& Katoh, M. (2006). FGF signaling inhibitor, SPRY4, is evolutionarily conserved target of WNT signaling pathway in progenitor cells. International Journal of Molecular Medicine, 17(3), 529-532.

14. Cabrita, M. A., \& Christofori, G. (2008). Sprouty proteins, masterminds of receptor tyrosine kinase signaling. Angiogenesis, 11(1), 53-62. doi:10.1007/s10456-008-9089-1.

15. Horowitz, A., \& Simons, M. (2008). Branching morphogenesis. [Research Support, N.I.H., Extramural Research Support, NonU.S. Gov't Review]. Circulation Research, 103(8), 784-795. doi: 10.1161/CIRCRESAHA.108.181818.

16. Warburton, D. (2008). Developmental biology: Order in the lung. Nature, 453(7196), 733-735. doi:10.1038/453733a.

17. Furthauer, M., Reifers, F., Brand, M., Thisse, B., \& Thisse, C. (2001). Sprouty4 acts in vivo as a feedback-induced antagonist of FGF signaling in zebrafish. [Research Support, Non-U.S. Gov't]. Development, 128(12), 2175-2186.

18. Zhang, S., Lin, Y., Itaranta, P., Yagi, A., \& Vainio, S. (2001). Expression of Sprouty genes 1, 2 and 4 during mouse organogenesis. Mechanisms of Development, 109(2), 367-370.

19. Gross, I., Morrison, D. J., Hyink, D. P., Georgas, K., English, M. A., Mericskay, M., et al. (2003). The receptor tyrosine kinase regulator Sprouty1 is a target of the tumor suppressor WT1 and important for kidney development. Journal of Biological Chemistry, 278(42), 41420-41430. doi:10.1074/jbc.M306425200.

20. Chi, L., Zhang, S., Lin, Y., Prunskaite-Hyyrylainen, R., Vuolteenaho, R., Itaranta, P., et al. (2004). Sprouty proteins regulate ureteric branching by coordinating reciprocal epithelial Wnt11, mesenchymal Gdnf and stromal Fgf7 signalling during kidney development. Development, 131(14), 3345-3356. doi:10.1242/dev.01200.

21. Lo, T. L., Yusoff, P., Fong, C. W., Guo, K., McCaw, B. J., Phillips, W. A., et al. (2004). The ras/mitogen-activated protein kinase 
pathway inhibitor and likely tumor suppressor proteins, sprouty 1 and sprouty 2 are deregulated in breast cancer. Cancer Research, 64(17), 6127-6136. doi:10.1158/0008-5472.CAN-04-1207.

22. Anteby, E. Y., Natanson-Yaron, S., Greenfield, C., Goldman-Wohl, D., Haimov-Kochman, R., Holzer, H., et al. (2005). Human placental Hofbauer cells express sprouty proteins: a possible modulating mechanism of villous branching. Placenta, 26(6), 476-483. doi:10. 1016/j.placenta.2004.08.008.

23. Haimov-Kochman, R., Ravhon, A., Prus, D., Greenfield, C., FinciYeheskel, Z., Goldman-Wohl, D. S., et al. (2005). Expression and regulation of Sprouty-2 in the granulosa-lutein cells of the corpus luteum. Molecular Human Reproduction, 11(8), 537-542. doi:10. 1093/molehr/gah203.

24. Lin, W., Jing, N., Basson, M. A., Dierich, A., Licht, J., \& Ang, S. L. (2005). Synergistic activity of Sef and Sprouty proteins in regulating the expression of Gbx2 in the mid-hindbrain region. Genesis, 41(3), 110-115. doi:10.1002/gene.20103.

25. Shim, K., Minowada, G., Coling, D. E., \& Martin, G. R. (2005). Sprouty2, a mouse deafness gene, regulates cell fate decisions in the auditory sensory epithelium by antagonizing FGF signaling. Developmental Cell, 8(4), 553-564. doi:10.1016/j.devcel.2005.02. 009.

26. Basson, M. A., Watson-Johnson, J., Shakya, R., Akbulut, S., Hyink, D., Costantini, F. D., et al. (2006). Branching morphogenesis of the ureteric epithelium during kidney development is coordinated by the opposing functions of GDNF and Sprouty1. Developmental Biology, 299(2), 466-477. doi:10.1016/j.ydbio.2006.08.051.

27. Boros, J., Newitt, P., Wang, Q., McAvoy, J. W., \& Lovicu, F. J. (2006). Sef and Sprouty expression in the developing ocular lens: Implications for regulating lens cell proliferation and differentiation. Seminars in Cell and Developmental Biology, 17(6), 741-752. doi: 10.1016/j.semcdb.2006.10.007.

28. Chi, L., Itaranta, P., Zhang, S., \& Vainio, S. (2006). Sprouty2 is involved in male sex organogenesis by controlling fibroblast growth factor 9-induced mesonephric cell migration to the developing testis. Endocrinology, 147(8), 3777-3788. doi:10.1210/en.20060299.

29. Natanson-Yaron, S., Anteby, E. Y., Greenfield, C., Goldman-Wohl, D., Hamani, Y., Hochner-Celnikier, D., et al. (2007). FGF 10 and Sprouty 2 modulate trophoblast invasion and branching morphogenesis. Molecular Human Reproduction, 13(7), 511-519. doi:10. 1093/molehr/gam034.

30. Price, K. L., Long, D. A., Jina, N., Liapis, H., Hubank, M., Woolf, A. S., et al. (2007). Microarray interrogation of human metanephric mesenchymal cells highlights potentially important molecules in vivo. Physiological Genomics, 28(2), 193-202. doi:10.1152/ physiolgenomics.00147.2006.

31. Shaw, A. T., Meissner, A., Dowdle, J. A., Crowley, D., Magendantz, M., Ouyang, C., et al. (2007). Sprouty-2 regulates oncogenic K-ras in lung development and tumorigenesis. Genes and Development, 21(6), 694-707. doi:10.1101/gad.1526207.

32. Laziz, I., Armand, A. S., Pariset, C., Lecolle, S., Della Gaspera, B., Charbonnier, F., et al. (2007). Sprouty gene expression is regulated by nerve and FGF6 during regeneration of mouse muscles. Growth Factors, 25(3), 151-159. doi:10.1080/08977190701723166.

33. Hamel, M., Dufort, I., Robert, C., Gravel, C., Leveille, M. C., Leader, A., et al. (2008). Identification of differentially expressed markers in human follicular cells associated with competent oocytes. Human Reproduction, 23(5), 1118-1127. doi:10.1093/ humrep/den048.

34. Klein, O. D., Lyons, D. B., Balooch, G., Marshall, G. W., Basson, M. A., Peterka, M., et al. (2008). An FGF signaling loop sustains the generation of differentiated progeny from stem cells in mouse incisors. Development, 135(2), 377-385. doi:10.1242/dev.015081.

35. Jaggi, F., Cabrita, M. A., Perl, A. K., \& Christofori, G. (2008). Modulation of endocrine pancreas development but not beta-cell carcinogenesis by Sprouty4. Molecular Cancer Research, 6(3), 468-482. doi:10.1158/1541-7786.mcr-07-0255.

36. Wang, Y., Janicki, P., Koster, I., Berger, C. D., Wenzl, C., Grosshans, J., et al. (2008). Xenopus paraxial protocadherin regulates morphogenesis by antagonizing Sprouty. Genes and Development, 22(7), 878-883. doi:10.1101/gad.452908.

37. Pan, Y., Carbe, C., Powers, A., Feng, G. S., \& Zhang, X. (2010). Sprouty2-modulated Kras signaling rescues Shp2 deficiency during lens and lacrimal gland development. Development, 137(7), 10851093. doi: $10.1242 /$ dev. 042820 .

38. Purcell, P., Jheon, A., Vivero, M. P., Rahimi, H., Joo, A., \& Klein, O. D. (2012). Spry1 and Spry2 are essential for development of the temporomandibular joint. Journal of Dental Research. doi:10.1177/ 0022034512438401

39. Sieglitz, F., Matzat, T., Yuva-Adyemir, Y., Neuert, H., Altenhein, B., \& Klambt, C. (2013). Antagonistic feedback loops involving rau and sprouty in the Drosophila eye control neuronal and glial differentiation. Science Signaling, 6(300), ra96. doi:10.1126/scisignal. 2004651.

40. Kuracha, M. R., Siefker, E., Licht, J. D., \& Govindarajan, V. (2013). Spry1 and Spry2 are necessary for eyelid closure. Developmental Biology, 383(2), 227-238. doi:10.1016/j.ydbio.2013.09.014.

41. Velasco, A., Pallares, J., Santacana, M., Gatius, S., Fernandez, M., Domingo, M., et al. (2011). Promoter hypermethylation and expression of sprouty 2 in endometrial carcinoma. Human Pathology, 42(2), 185-193. doi:10.1016/j.humpath.2010.08.001.

42. Sigurdsson, V., Ingthorsson, S., Hilmarsdottir, B., Gustafsdottir, S. M., Franzdottir, S. R., Arason, A. J., et al. (2013). Expression and functional role of sprouty-2 in breast morphogenesis. PLoS One, 8(4), e60798. doi:10.1371/journal.pone.0060798.

43. Ching, S. T., Cunha, G. R., Baskin, L. S., Basson, M. A., \& Klein, O. D. (2014). Coordinated activity of Spry1 and Spry2 is required for normal development of the external genitalia. Developmental Biology, 386(1), 1-11. doi:10.1016/j.ydbio.2013.12.014.

44. Lee, S. H., Schloss, D. J., Jarvis, L., Krasnow, M. A., \& Swain, J. L. (2001). Inhibition of angiogenesis by a mouse sprouty protein. Journal of Biological Chemistry, 276(6), 4128-4133. doi:10.1074/ jbc.M006922200.

45. Huebert, R. C., Li, Q., Adhikari, N., Charles, N. J., Han, X., Ezzat, M. K., et al. (2004). Identification and regulation of Sprouty1, a negative inhibitor of the ERK cascade, in the human heart. Physiological Genomics, 18(3), 284-289. doi:10.1152/ physiolgenomics.00098.2004.

46. Poppleton, H. M., Edwin, F., Jaggar, L., Ray, R., Johnson, L. R., \& Patel, T. B. (2004). Sprouty regulates cell migration by inhibiting the activation of Rac1 GTPase. Biochemical and Biophysical Research Communications, 323(1), 98-103. doi:10.1016/j.bbrc. 2004.08.070.

47. Zhang, C., Chaturvedi, D., Jaggar, L., Magnuson, D., Lee, J. M., \& Patel, T. B. (2005). Regulation of vascular smooth muscle cell proliferation and migration by human sprouty 2. Arteriosclerosis, Thrombosis, and Vascular Biology, 25(3), 533-538. doi:10.1161/01. ATV.0000155461.50450.5a.

48. de Alvaro, C., Martinez, N., Rojas, J. M., \& Lorenzo, M. (2005). Sprouty-2 overexpression in C2C12 cells confers myogenic differentiation properties in the presence of FGF2. Molecular Biology of the Cell, 16(9), 4454-4461. doi:10. 1091/mbc.E05-05-0419.

49. Tsumura, Y., Toshima, J., Leeksma, O. C., Ohashi, K., \& Mizuno, K. (2005). Sprouty-4 negatively regulates cell spreading by inhibiting the kinase activity of testicular protein kinase. Biochemical Journal, 387(Pt 3), 627-637. doi:10.1042/ BJ20041181.

50. Fong, C. W., Chua, M. S., McKie, A. B., Ling, S. H., Mason, V., Li, R., et al. (2006). Sprouty 2, an inhibitor of mitogen-activated protein kinase signaling, is down-regulated in hepatocellular carcinoma. 
Cancer Research, 66(4), 2048-2058. doi:10.1158/0008-5472. CAN-05-1072.

51. Wang, J., Thompson, B., Ren, C., Ittmann, M., \& Kwabi-Addo, B. (2006). Sprouty4, a suppressor of tumor cell motility, is down regulated by DNA methylation in human prostate cancer. Prostate, 66(6), 613-624. doi:10.1002/pros.20353.

52. Sutterluty, H., Mayer, C. E., Setinek, U., Attems, J., Ovtcharov, S., Mikula, M., et al. (2007). Down-regulation of Sprouty2 in nonsmall cell lung cancer contributes to tumor malignancy via extracellular signal-regulated kinase pathway-dependent and independent mechanisms. Molecular Cancer Research, 5(5), 509520. doi:10.1158/1541-7786.MCR-06-0273.

53. Ding, W., Shi, W., Bellusci, S., Groffen, J., Heisterkamp, N., Minoo, P., et al. (2007). Sprouty2 downregulation plays a pivotal role in mediating crosstalk between TGF-betal signaling and EGF as well as FGF receptor tyrosine kinase-ERK pathways in mesenchymal cells. Journal of Cellular Physiology, 212(3), 796-806. doi:10. 1002/jcp. 21078.

54. Ding, W., \& Warburton, D. (2008). Down-regulation of Sprouty2 via p38 MAPK plays a key role in the induction of cellular apoptosis by tumor necrosis factor-alpha. Biochemical and Biophysical Research Communications, 375(3), 460-464. doi:10.1016/j.bbrc. 2008.08.037.

55. Lito, P., Mets, B. D., Appledorn, D. M., Maher, V. M., \& McCormick, J. J. (2009). Sprouty 2 regulates DNA damageinduced apoptosis in Ras-transformed human fibroblasts. Journal of Biological Chemistry, 284(2), 848-854. doi:10.1074/jbc. M808045200.

56. Tennis, M. A., Van Scoyk, M. M., Freeman, S. V., Vandervest, K. M., Nemenoff, R. A., \& Winn, R. A. (2010). Sprouty-4 inhibits transformed cell growth, migration and invasion, and epithelialmesenchymal transition, and is regulated by Wnt7A through PPARgamma in non-small cell lung cancer. Molecular Cancer Research, 8(6), 833-843. doi:10.1158/1541-7786.mcr-09-0400.

57. Jung, J. E., Moon, S. H., Kim, D. K., Choi, C., Song, J., \& Park, K. S. (2012). Sprouty1 regulates neural and endothelial differentiation of mouse embryonic stem cells. Stem Cells and Development, 21(4), 554-561. doi:10.1089/scd.2011.0110.

58. Felfly, H., \& Klein, O. D. (2013). Sprouty genes regulate proliferation and survival of human embryonic stem cells. Science Reports, 3, 2277. doi:10.1038/srep02277.

59. Mekkawy, A. H., \& Morris, D. L. (2013). Human Sprouty1 suppresses urokinase receptor-stimulated cell migration and invasion. ISRN Biochem, 2013, 7. doi:10.1155/2013/598251.

60. Sasaki, A., Taketomi, T., Wakioka, T., Kato, R., \& Yoshimura, A. (2001). Identification of a dominant negative mutant of Sprouty that potentiates fibroblast growth factor-but not epidermal growth factor-induced ERK activation. Journal of Biological Chemistry, 276(39), 36804-36808. doi:10.1074/jbc.C100386200.

61. Yigzaw, Y., Cartin, L., Pierre, S., Scholich, K., \& Patel, T. B. (2001). The $\mathrm{C}$ terminus of sprouty is important for modulation of cellular migration and proliferation. Journal of Biological Chemistry, 276(25), 22742-22747. doi:10.1074/jbc.M100123200.

62. Yigzaw, Y., Poppleton, H. M., Sreejayan, N., Hassid, A., \& Patel, T. B. (2003). Protein-tyrosine phosphatase-1B (PTP1B) mediates the anti-migratory actions of Sprouty. Journal of Biological Chemistry, 278(1), 284-288. doi:10.1074/jbc.M210359200.

63. Lee, C. C., Putnam, A. J., Miranti, C. K., Gustafson, M., Wang, L. M., Vande Woude, G. F., et al. (2004). Overexpression of sprouty 2 inhibits HGF/SF-mediated cell growth, invasion, migration, and cytokinesis. Oncogene, 23(30), 5193-5202. doi:10.1038/sj.onc. 1207646.

64. Edwin, F., Singh, R., Endersby, R., Baker, S. J., \& Patel, T. B. (2006). The tumor suppressor PTEN is necessary for human Sprouty 2-mediated inhibition of cell proliferation. Journal of
Biological Chemistry, 281(8), 4816-4822. doi:10.1074/jbc. M508300200.

65. Edwin, F., \& Patel, T. B. (2008). A novel role of Sprouty 2 in regulating cellular apoptosis. Journal of Biological Chemistry, 283(6), 3181-3190. doi:10.1074/jbc.M706567200.

66. Lee, S. A., Ho, C., Roy, R., Kosinski, C., Patil, M. A., Tward, A. D., et al. (2008). Integration of genomic analysis and in vivo transfection to identify sprouty 2 as a candidate tumor suppressor in liver cancer. Hepatology, 47(4), 1200-1210. doi:10.1002/hep.22169.

67. Frank, M. J., Dawson, D. W., Bensinger, S. J., Hong, J. S., Knosp, W. M., Xu, L., et al. (2009). Expression of sprouty2 inhibits B-cell proliferation and is epigenetically silenced in mouse and human Bcell lymphomas. Blood, 113(11), 2478-2487. doi:10.1182/blood2008-05-156943.

68. Holgren, C., Dougherty, U., Edwin, F., Cerasi, D., Taylor, I., Fichera, A., et al. (2010). Sprouty-2 controls c-Met expression and metastatic potential of colon cancer cells: sprouty/c-Met upregulation in human colonic adenocarcinomas. [Research Support, N.I.H., Extramural Research Support, U.S. Gov't, Non-P.H.S.]. Oncogene, 29(38), 5241-5253. doi:10.1038/onc.2010.264.

69. Barbachano, A., Ordonez-Moran, P., Garcia, J. M., Sanchez, A., Pereira, F., Larriba, M. J., et al. (2010). SPROUTY-2 and E-cadherin regulate reciprocally and dictate colon cancer cell tumourigenicity. Oncogene, 29(34), 4800-4813. doi:10.1038/onc.2010.225.

70. Schaaf, G., Hamdi, M., Zwijnenburg, D., Lakeman, A., Geerts, D., Versteeg, R., et al. (2010). Silencing of SPRY1 triggers complete regression of rhabdomyosarcoma tumors carrying a mutated RAS gene. Cancer Research, 70(2), 762-771. doi:10.1158/0008-5472. can-09-2532.

71. Wang, C., Delogu, S., Ho, C., Lee, S. A., Gui, B., Jiang, L., et al. (2012). Inactivation of Spry 2 accelerates AKT-driven hepatocarcinogenesis via activation of MAPK and PKM2 pathways. Journal of Hepatology, 57(3), 577-583. doi:10.1016/j.jhep. 2012.04.026.

72. Alsina, F. C., Irala, D., Fontanet, P. A., Hita, F. J., Ledda, F., \& Paratcha, G. (2012). Sprouty4 is an endogenous negative modulator of TrkA signaling and neuronal differentiation induced by NGF. PLoS One, 7(2), e32087. doi:10.1371/journal.pone.0032087.

73. Schlessinger, J. (2004). Common and distinct elements in cellular signaling via EGF and FGF receptors. Science, 306(5701), 15061507. doi:10.1126/science. 1105396.

74. Marshall, C. J. (1995). Specificity of receptor tyrosine kinase signaling: transient versus sustained extracellular signal-regulated kinase activation. Cell, 80(2), 179-185.

75. Kim, H. J., \& Bar-Sagi, D. (2004). Modulation of signalling by Sprouty: a developing story. Nature Reviews Molecular Cell Biology, 5(6), 441-450. doi:10.1038/nrm1400.

76. Sasaki, A., Taketomi, T., Kato, R., Saeki, K., Nonami, A., Sasaki, M., et al. (2003). Mammalian Sprouty4 suppresses Ras-independent ERK activation by binding to Raf1. Nature Cell Biology, 5(5), 427432. doi:10.1038/ncb978.

77. Kao, S., Jaiswal, R. K., Kolch, W., \& Landreth, G. E. (2001). Identification of the mechanisms regulating the differential activation of the mapk cascade by epidermal growth factor and nerve growth factor in PC12 cells. Journal of Biological Chemistry, 276(21), 18169-18177. doi:10.1074/jbc.M008870200.

78. Ozaki, K., Kadomoto, R., Asato, K., Tanimura, S., Itoh, N., \& Kohno, M. (2001). ERK pathway positively regulates the expression of Sprouty genes. [Research Support, Non-U.S. Gov't]. Biochemical and Biophysical Research Communications, 285(5), 1084-1088. doi:10.1006/bbrc.2001.5295.

79. Kral, R. M., Mayer, C. E., Vanas, V., Gsur, A., \& Sutterluty-Fall, H. (2013). In non-small cell lung cancer mitogenic signaling leaves Sprouty1 protein levels unaffected. Cell Biochemistry and Function. doi:10.1002/cbf.2976. 
80. Hausott, B., Vallant, N., Auer, M., Yang, L., Dai, F., Brand-Saberi, B., et al. (2009). Sprouty2 down-regulation promotes axon growth by adult sensory neurons. Molecular and Cellular Neuroscience, 42(4), 328-340. doi:10.1016/j.mcn.2009.08.005.

81. Shea, K. L., Xiang, W., LaPorta, V. S., Licht, J. D., Keller, C., Basson, M. A., et al. (2010). Sprouty1 regulates reversible quiescence of a self-renewing adult muscle stem cell pool during regeneration. Cell Stem Cell, 6(2), 117-129. doi:10.1016/j.stem.2009.12. 015.

82. Choi, H., Cho, S. Y., Schwartz, R. H., \& Choi, K. (2006). Dual effects of Sprouty1 on TCR signaling depending on the differentiation state of the T cell. Journal of Immunology, 176(10), 6034 6045 .

83. Jiang, Z., \& Price, C. A. (2012). Differential actions of fibroblast growth factors on intracellular pathways and target gene expression in bovine ovarian granulosa cells. Reproduction, 144(5), 625-632. doi:10.1530/rep-12-0199.

84. Jiang, Z., Guerrero-Netro, H. M., Juengel, J. L., \& Price, C. A. (2013). Divergence of intracellular signaling pathways and early response genes of two closely related fibroblast growth factors, FGF8 and FGF18, in bovine ovarian granulosa cells. Molecular and Cellular Endocrinology, 375(1-2), 97-105. doi:10.1016/j.mce. 2013.05.017.

85. Ding, W., Bellusci, S., Shi, W., \& Warburton, D. (2003). Functional analysis of the human Sprouty2 gene promoter. [Research Support, Non-U.S. Gov't Research Support, U.S. Gov't, P.H.S.]. Gene, 322, 175-185.

86. Sabatel, C., Cornet, A. M., Tabruyn, S. P., Malvaux, L., Castermans, K., Martial, J. A., et al. (2010). Sprouty1, a new target of the angiostatic agent $16 \mathrm{~K}$ prolactin, negatively regulates angiogenesis. Molecular Cancer, 9, 231. doi:10.1186/1476-4598-9-231.

87. Hall, A. B., Jura, N., DaSilva, J., Jang, Y. J., Gong, D., \& Bar-Sagi, D. (2003). hSpry2 is targeted to the ubiquitin-dependent proteasome pathway by c-Cbl. [Research Support, Non-U.S. Gov't Research Support, U.S. Gov't, P.H.S.]. Current Biology, 13(4), 308-314.

88. Rubin, C., Litvak, V., Medvedovsky, H., Zwang, Y., Lev, S., \& Yarden, Y. (2003). Sprouty fine-tunes EGF signaling through interlinked positive and negative feedback loops. [Research Support, Non-U.S. Gov't Research Support, U.S. Gov't, P.H.S.]. Current Biology, 13(4), 297-307.

89. Mason, J. M., Morrison, D. J., Bassit, B., Dimri, M., Band, H., Licht, J. D., et al. (2004). Tyrosine phosphorylation of Sprouty proteins regulates their ability to inhibit growth factor signaling: a dual feedback loop. [Research Support, Non-U.S. Gov't Research Support, U.S. Gov't, Non-P.H.S. Research Support, U.S. Gov't, P.H.S.]. Molecular Biology of the Cell, 15(5), 2176-2188. doi:10. 1091/mbc.E03-07-0503.

90. Mason, J. M., Morrison, D. J., Basson, M. A., \& Licht, J. D. (2006). Sprouty proteins: multifaceted negative-feedback regulators of receptor tyrosine kinase signaling. [Research Support, N.I.H., Extramural Research Support, Non-U.S. Gov't Review]. Trends in Cell Biology, 16(1), 45-54. doi:10.1016/j.tcb.2005.11.004.

91. Mayer, C. E., Haigl, B., Jantscher, F., Siegwart, G., Grusch, M., Berger, W., et al. (2010). Bimodal expression of Sprouty2 during the cell cycle is mediated by phase-specific Ras/MAPK and c-Cbl activities. Cellular and Molecular Life Sciences, 67(19), 32993311. doi:10.1007/s00018-010-0379-6.

92. DaSilva, J., Xu, L., Kim, H. J., Miller, W. T., \& Bar-Sagi, D. (2006). Regulation of sprouty stability by Mnk1-dependent phosphorylation. Molecular and Cellular Biology, 26(5), 1898-1907. doi:10. 1128/MCB.26.5.1898-1907.2006.

93. Edwin, F., Anderson, K., \& Patel, T. B. (2010). HECT domaincontaining E3 ubiquitin ligase Nedd4 interacts with and ubiquitinates Sprouty2. Journal of Biological Chemistry, 285(1), 255-264. doi:10.1074/jbc.M109.030882.
94. Nadeau, R. J., Toher, J. L., Yang, X., Kovalenko, D., \& Friesel, R. (2007). Regulation of Sprouty2 stability by mammalian Seven-inAbsentia homolog 2. Journal of Cellular Biochemistry, 100(1), 151-160. doi:10.1002/jcb.21040.

95. Qi, J., Nakayama, K., Gaitonde, S., Goydos, J. S., Krajewski, S., Eroshkin, A., et al. (2008). The ubiquitin ligase Siah2 regulates tumorigenesis and metastasis by HIF-dependent and -independent pathways. Proceedings of the National Academy of Sciences of the United States of America, 105(43), 16713-16718. doi:10.1073/ pnas.0804063105.

96. Haigl, B., Mayer, C. E., Siegwart, G., \& Sutterluty, H. (2010). Sprouty4 levels are increased under hypoxic conditions by enhanced mRNA stability and transcription. Biological Chemistry, 391(7), 813-821. doi:10.1515/bc.2010.082.

97. Anderson, K., Nordquist, K. A., Gao, X., Hicks, K. C., Zhai, B., Gygi, S. P., et al. (2011). Regulation of cellular levels of Sprouty2 protein by prolyl hydroxylase domain and von Hippel-Lindau proteins. [Research Support, N.I.H., Extramural]. Journal of Biological Chemistry, 286(49), 42027-42036. doi:10.1074/jbc.M111.303222.

98. Lim, J., Wong, E. S., Ong, S. H., Yusoff, P., Low, B. C., \& Guy, G. R. (2000). Sprouty proteins are targeted to membrane ruffles upon growth factor receptor tyrosine kinase activation. Identification of a novel translocation domain. Journal of Biological Chemistry, 275(42), 32837-32845. doi:10.1074/jbc.M002156200.

99. Hanafusa, H., Torii, S., Yasunaga, T., \& Nishida, E. (2002). Sprouty1 and Sprouty2 provide a control mechanism for the Ras/ MAPK signalling pathway. [Research Support, Non-U.S. Gov't]. Nature Cell Biology, 4(11), 850-858. doi:10.1038/ncb867.

100. Lim, J., Yusoff, P., Wong, E. S., Chandramouli, S., Lao, D. H., Fong, C. W., et al. (2002). The cysteine-rich sprouty translocation domain targets mitogen-activated protein kinase inhibitory proteins to phosphatidylinositol 4,5-bisphosphate in plasma membranes. Molecular and Cellular Biology, 22(22), 7953-7966.

101. Cabrita, M. A., Jaggi, F., Widjaja, S. P., \& Christofori, G. (2006). A functional interaction between sprouty proteins and caveolin-1. Journal of Biological Chemistry, 281(39), 29201-29212. doi:10. 1074/jbc.M603921200.

102. Hwangpo, T. A., Jordan, J. D., Premsrirut, P. K., Jayamaran, G., Licht, J. D., Iyengar, R., et al. (2012). G Protein-regulated inducer of neurite outgrowth (GRIN) modulates Sprouty protein repression of mitogen-activated protein kinase (MAPK) activation by growth factor stimulation. Journal of Biological Chemistry, 287(17), 13674-13685. doi:10.1074/jbc.M111.320705.

103. Fong, C. W., Leong, H. F., Wong, E. S., Lim, J., Yusoff, P., \& Guy, G. R. (2003). Tyrosine phosphorylation of Sprouty2 enhances its interaction with $\mathrm{c}-\mathrm{Cbl}$ and is crucial for its function. [Research Support, Non-U.S. Gov't]. Journal of Biological Chemistry, 278(35), 33456-33464. doi:10.1074/jbc.M301317200.

104. Rubin, C., Zwang, Y., Vaisman, N., Ron, D., \& Yarden, Y. (2005). Phosphorylation of carboxyl-terminal tyrosines modulates the specificity of Sprouty-2 inhibition of different signaling pathways. Journal of Biological Chemistry, 280(10), 9735-9744. doi:10. 1074/jbc.M408308200.

105. Lao, D. H., Yusoff, P., Chandramouli, S., Philp, R. J., Fong, C. W., Jackson, R. A., et al. (2007). Direct binding of PP2A to Sprouty2 and phosphorylation changes are a prerequisite for ERK inhibition downstream of fibroblast growth factor receptor stimulation. Journal of Biological Chemistry, 282(12), 9117-9126. doi:10. 1074/jbc.M607563200.

106. Lao, D. H., Chandramouli, S., Yusoff, P., Fong, C. W., Saw, T. Y., Tai, L. P., et al. (2006). A Src homology 3-binding sequence on the $\mathrm{C}$ terminus of Sprouty2 is necessary for inhibition of the Ras/ERK pathway downstream of fibroblast growth factor receptor stimulation. Journal of Biological Chemistry, 281(40), 29993-30000. doi: 10.1074/jbc.M604044200. 
107. Chandramouli, S., Yu, C. Y., Yusoff, P., Lao, D. H., Leong, H. F., Mizuno, K., et al. (2008). Tesk1 interacts with Spry2 to abrogate its inhibition of ERK phosphorylation downstream of receptor tyrosine kinase signaling. Journal of Biological Chemistry, 283(3), 16791691. doi:10.1074/jbc.M705457200.

108. Hanafusa, H., Torii, S., Yasunaga, T., Matsumoto, K., \& Nishida, E. (2004). Shp2, an SH2-containing protein-tyrosine phosphatase, positively regulates receptor tyrosine kinase signaling by dephosphorylating and inactivating the inhibitor Sprouty. Journal of Biological Chemistry, 279(22), 22992-22995. doi:10.1074/jbc.M312498200.

109. Jarvis, L. A., Toering, S. J., Simon, M. A., Krasnow, M. A., \& Smith-Bolton, R. K. (2006). Sprouty proteins are in vivo targets of Corkscrew/SHP-2 tyrosine phosphatases. Development, 133(6), 1133-1142. doi:10.1242/dev.02255.

110. Patel, R., Gao, M., Ahmad, I., Fleming, J., Singh, L. B., Rai, T. S., et al. (2013). Sprouty2, PTEN, and PP2A interact to regulate prostate cancer progression. Journal of Clinical Investigation, 123(3), 1157-1175. doi:10.1172/jci63672.

111. Haj, F. G., Verveer, P. J., Squire, A., Neel, B. G., \& Bastiaens, P. I. (2002). Imaging sites of receptor dephosphorylation by PTP1B on the surface of the endoplasmic reticulum. Science, 295(5560), 1708-1711. doi:10.1126/science.1067566.

112. Egan, J. E., Hall, A. B., Yatsula, B. A., \& Bar-Sagi, D. (2002). The bimodal regulation of epidermal growth factor signaling by human Sprouty proteins. Proceedings of the National Academy of Sciences of the United States of America, 99(9), 6041-6046. doi:10.1073/ pnas.052090899.

113. Wong, E. S., Lim, J., Low, B. C., Chen, Q., \& Guy, G. R. (2001). Evidence for direct interaction between Sprouty and Cbl. Journal of Biological Chemistry, 276(8), 5866-5875. doi:10.1074/jbc. M006945200.

114. Kim, H. J., Taylor, L. J., \& Bar-Sagi, D. (2007). Spatial regulation of EGFR signaling by Sprouty2. Current Biology, 17(5), 455-461. doi: 10.1016/j.cub.2007.01.059.

115. Aranda, S., Alvarez, M., Turro, S., Laguna, A., \& de la Luna, S. (2008). Sprouty2-mediated inhibition of fibroblast growth factor signaling is modulated by the protein kinase DYRK1A. Molecular and Cellular Biology, 28(19), 5899-5911. doi:10.1128/MCB. 00394-08.

116. Reich, A., Sapir, A., \& Shilo, B. (1999). Sprouty is a general inhibitor of receptor tyrosine kinase signaling. [Research Support, Non-U.S. Gov't]. Development, 126(18), 4139-4147.

117. Tsavachidou, D., Coleman, M. L., Athanasiadis, G., Li, S. X., Licht, J. D., Olson, M. F., et al. (2004). SPRY2 is an inhibitor of the Ras/ extracellular signal-regulated kinase pathway in melanocytes and melanoma cells with wild-type BRAF but not with the V599E mutant. Cancer Research, 64(16), 5556-5559.

118. Yusoff, P., Lao, D. H., Ong, S. H., Wong, E. S., Lim, J., Lo, T. L., et al. (2002). Sprouty2 inhibits the Ras/MAP kinase pathway by inhibiting the activation of Raf. Journal of Biological Chemistry, 277(5), 3195-3201. doi:10.1074/jbc.M108368200.

119. Ayada, T., Taniguchi, K., Okamoto, F., Kato, R., Komune, S., Takaesu, G., et al. (2009). Sprouty4 negatively regulates protein kinase $\mathrm{C}$ activation by inhibiting phosphatidylinositol 4,5biphosphate hydrolysis. Oncogene, 28(8), 1076-1088. doi:10. 1038/onc.2008.464.

120. Taniguchi, K., Ishizaki, T., Ayada, T., Sugiyama, Y., Wakabayashi, Y., Sekiya, T., et al. (2009). Sprouty4 deficiency potentiates Rasindependent angiogenic signals and tumor growth. Cancer Science, 100(9), 1648-1654. doi:10.1111/j.1349-7006.2009.01214.x.

121. Haglund, K., Di Fiore, P. P., \& Dikic, I. (2003). Distinct monoubiquitin signals in receptor endocytosis. Trends in Biochemical Sciences, 28(11), 598-603. doi:10.1016/j.tibs.2003. 09.005 .

122. Haglund, K., Sigismund, S., Polo, S., Szymkiewicz, I., Di Fiore, P. P., \& Dikic, I. (2003). Multiple monoubiquitination of RTKs is sufficient for their endocytosis and degradation. Nature Cell Biology, 5(5), 461-466. doi:10.1038/ncb983.

123. Mosesson, Y., Shtiegman, K., Katz, M., Zwang, Y., Vereb, G., Szollosi, J., et al. (2003). Endocytosis of receptor tyrosine kinases is driven by monoubiquitylation, not polyubiquitylation. Journal of Biological Chemistry, 278(24), 21323-21326. doi:10.1074/jbc. C300096200.

124. Petrelli, A., Gilestro, G. F., Lanzardo, S., Comoglio, P. M., Migone, N., \& Giordano, S. (2002). The endophilin-CIN85-Cbl complex mediates ligand-dependent downregulation of c-Met. Nature, 416(6877), 187-190. doi:10.1038/416187a.

125. Soubeyran, P., Kowanetz, K., Szymkiewicz, I., Langdon, W. Y., \& Dikic, I. (2002). Cbl-CIN85-endophilin complex mediates ligandinduced downregulation of EGF receptors. Nature, 416(6877), 183187. doi:10.1038/416183a.

126. Kowanetz, K., Szymkiewicz, I., Haglund, K., Kowanetz, M., Husnjak, K., Taylor, J. D., et al. (2003). Identification of a novel proline-arginine motif involved in CIN85-dependent clustering of $\mathrm{Cbl}$ and down-regulation of epidermal growth factor receptors. Journal of Biological Chemistry, 278(41), 39735-39746. doi:10. 1074/jbc.M304541200.

127. Ng, C., Jackson, R. A., Buschdorf, J. P., Sun, Q., Guy, G. R., \& Sivaraman, J. (2008). Structural basis for a novel intrapeptidyl Hbond and reverse binding of c-Cbl-TKB domain substrates. EMBO Journal, 27(5), 804-816. doi:10.1038/emboj.2008.18.

128. Haglund, K., Schmidt, M. H., Wong, E. S., Guy, G. R., \& Dikic, I. (2005). Sprouty 2 acts at the $\mathrm{Cbl} / \mathrm{CIN} 85$ interface to inhibit epidermal growth factor receptor downregulation. EMBO Reports, 6(7), 635-641. doi:10.1038/sj.embor.7400453.

129. Ozaki, K., Miyazaki, S., Tanimura, S., \& Kohno, M. (2005). Efficient suppression of FGF-2-induced ERK activation by the cooperative interaction among mammalian Sprouty isoforms. Journal of Cell Science, 118(Pt 24), 5861-5871. doi:10.1242/jcs. 02711.

130. Frolov, A., Chahwan, S., Ochs, M., Arnoletti, J. P., Pan, Z. Z., Favorova, O., et al. (2003). Response markers and the molecular mechanisms of action of Gleevec in gastrointestinal stromal tumors. Molecular Cancer Therapeutics, 2(8), 699-709.

131. Feng, Y. H., Tsao, C. J., Wu, C. L., Chang, J. G., Lu, P. J., Yeh, K. T., et al. (2010). Sprouty2 protein enhances the response to gefitinib through epidermal growth factor receptor in colon cancer cells. Cancer Science, 101(9), 2033-2038. doi:10.1111/j.1349-7006. 2010.01637.x.

132. Faratian, D., Sims, A. H., Mullen, P., Kay, C., Um, I., Langdon, S. P., et al. (2011). Sprouty 2 is an independent prognostic factor in breast cancer and may be useful in stratifying patients for trastuzumab therapy. PLoS One, 6(8), e23772. doi:10.1371/ journal.pone.0023772.

133. Sirivatanauksorn, Y., Sirivatanauksorn, V., Srisawat, C., Khongmanee, A., \& Tongkham, C. (2012). Differential expression of sprouty genes in hepatocellular carcinoma. Journal of Surgical Oncology, 105(3), 273-276. doi:10.1002/jso.22095.

134. Song, K., Gao, Q., Zhou, J., Qiu, S. J., Huang, X. W., Wang, X. Y., et al. (2012). Prognostic significance and clinical relevance of Sprouty 2 protein expression in human hepatocellular carcinoma. [Research Support, Non-U.S. Gov't]. Hepatobiliary \& Pancreatic Diseases International, 11(2), 177-184.

135. McKie, A. B., Douglas, D. A., Olijslagers, S., Graham, J., Omar, M. M., Heer, R., et al. (2005). Epigenetic inactivation of the human sprouty2 (hSPRY2) homologue in prostate cancer. Oncogene, 24(13), 2166-2174. doi:10.1038/sj.onc. 1208371.

136. Winn, R. A., Marek, L., Han, S. Y., Rodriguez, K., Rodriguez, N., Hammond, M., et al. (2005). Restoration of Wnt-7a expression reverses non-small cell lung cancer cellular transformation through frizzled-9-mediated growth inhibition and promotion of cell differentiation. [Research Support, N.I.H., Extramural Research Support, 
U.S. Gov't, Non-P.H.S. Research Support, U.S. Gov't, P.H.S.]. Journal of Biological Chemistry, 280(20), 19625-19634. doi:10. 1074/jbc.M409392200.

137. Feng, Y. H., Wu, C. L., Tsao, C. J., Chang, J. G., Lu, P. J., Yeh, K. T., et al. (2011). Deregulated expression of sprouty 2 and microRNA-21 in human colon cancer: Correlation with the clinical stage of the disease. Cancer Biology and Therapy, 11(1), 111-121.

138. Dorman, K., Shen, Z., Yang, C., Ezzat, S., \& Asa, S. L. (2012). CtBP1 interacts with Ikaros and modulates pituitary tumor cell survival and response to hypoxia. Molecular Endocrinology, 26(3), 447-457. doi:10.1210/me.2011-1095.

139. Macia, A., Gallel, P., Vaquero, M., Gou-Fabregas, M., Santacana, M., Maliszewska, A., et al. (2012). Sprouty1 is a candidate tumorsuppressor gene in medullary thyroid carcinoma. Oncogene, 31(35), 3961-3972. doi:10.1038/onc.2011.556.

140. Schutzman, J. L., \& Martin, G. R. (2012). Sprouty genes function in suppression of prostate tumorigenesis. Proceedings of the National Academy of Sciences of the United States of America, 109(49), 20023-20028. doi:10.1073/pnas.1217204109.

141. Lito, P., Mets, B. D., Kleff, S., O'Reilly, S., Maher, V. M., \& McCormick, J. J. (2008). Evidence that sprouty 2 is necessary for sarcoma formation by H-Ras oncogene-transformed human fibroblasts. Journal of Biological Chemistry, 283(4), 2002-2009. doi:10. 1074/jbc.M709046200.

142. Kanetsky, P. A., Mitra, N., Vardhanabhuti, S., Li, M., Vaughn, D. J., Letrero, R., et al. (2009). Common variation in KITLG and at $5 \mathrm{q} 31.3$ predisposes to testicular germ cell cancer. Nature Genetics, 41(7), 811-815. doi:10.1038/ng.393.

143. Kwabi-Addo, B., Wang, J., Erdem, H., Vaid, A., Castro, P., Ayala, G., et al. (2004). The expression of Sprouty1, an inhibitor of fibroblast growth factor signal transduction, is decreased in human prostate cancer. Cancer Research, 64(14), 4728-4735. doi:10.1158/ 0008-5472.CAN-03-3759.

144. Minowada, G., \& Miller, Y. E. (2009). Overexpression of Sprouty 2 in mouse lung epithelium inhibits urethane-induced tumorigenesis. American Journal of Respiratory Cell and Molecular Biology, 40(1), 31-37. doi:10.1165/rcmb.2008-0147OC.

145. Mekkawy, A. H., De Bock, C. E., Lin, Z., Morris, D. L., Wang, Y., \& Pourgholami, M. H. (2010). Novel protein interactors of urokinase-type plasminogen activator receptor. Biochemical and Biophysical Research Communications, 399(4), 738-743. doi:10. 1016/j.bbrc.2010.08.010.

146. Vanas, V., Muhlbacher, E., Kral, R., \& Sutterluty-Fall, H. (2014). Sprouty4 interferes with cell proliferation and migration of breast cancer-derived cell lines. Tumour Biology. doi:10.1007/s13277013-1587-0.

147. Kwabi-Addo, B., Ren, C., \& Ittmann, M. (2009). DNA methylation and aberrant expression of Sprouty1 in human prostate cancer. [Research Support, N.I.H., Extramural Research Support, U.S. Gov't, Non-P.H.S.]. Epigenetics, 4(1), 54-61.

148. Taylor, B. S., Schultz, N., Hieronymus, H., Gopalan, A., Xiao, Y., Carver, B. S., et al. (2010). Integrative genomic profiling of human prostate cancer. Cancer Cell, 18(1), 11-22. doi:10.1016/j.ccr.2010. 05.026.

149. Fritzsche, S., Kenzelmann, M., Hoffmann, M. J., Muller, M., Engers, R., Grone, H. J., et al. (2006). Concomitant downregulation of SPRY1 and SPRY2 in prostate carcinoma. Endocrine-Related Cancer, 13(3), 839-849. doi:10.1677/erc.1. 01190.

150. Yap, T. A., Zivi, A., Omlin, A., \& de Bono, J. S. (2011). The changing therapeutic landscape of castration-resistant prostate cancer. Nature Reviews. Clinical Oncology, 8(10), 597-610. doi:10. 1038/nrclinonc.2011.117.

151. Di Cristofano, A., Pesce, B., Cordon-Cardo, C., \& Pandolfi, P. P. (1998). Pten is essential for embryonic development and tumour suppression. Nature Genetics, 19(4), 348-355. doi:10.1038/1235.
152. Chen, X., Cheung, S. T., So, S., Fan, S. T., Barry, C., Higgins, J., et al. (2002). Gene expression patterns in human liver cancers. Molecular Biology of the Cell, 13(6), 1929-1939. doi:10.1091/ mbc.02-02-0023.

153. Harada, N., Miyoshi, H., Murai, N., Oshima, H., Tamai, Y., Oshima, M., et al. (2002). Lack of tumorigenesis in the mouse liver after adenovirus-mediated expression of a dominant stable mutant of beta-catenin. Cancer Research, 62(7), 1971-1977.

154. Harada, N., Oshima, H., Katoh, M., Tamai, Y., Oshima, M., \& Taketo, M. M. (2004). Hepatocarcinogenesis in mice with betacatenin and Ha-ras gene mutations. Cancer Research, 64(1), 48-54.

155. Lee, S. A., Ladu, S., Evert, M., Dombrowski, F., De Murtas, V., Chen, X., et al. (2010). Synergistic role of Sprouty2 inactivation and c-Met up-regulation in mouse and human hepatocarcinogenesis. Hepatology, 52(2), 506-517. doi:10.1002/hep.23681.

156. Cho, H. C., Lai, C. Y., Shao, L. E., \& Yu, J. (2011). Identification of tumorigenic cells in $\mathrm{Kras}(\mathrm{G} 12 \mathrm{D})$-induced lung adenocarcinoma. Cancer Research, 71(23), 7250-7258. doi:10.1158/0008-5472. can-11-0903.

157. Bren-Mattison, Y., Van Putten, V., Chan, D., Winn, R., Geraci, M. W., \& Nemenoff, R. A. (2005). Peroxisome proliferator-activated receptor-gamma (PPAR(gamma)) inhibits tumorigenesis by reversing the undifferentiated phenotype of metastatic non-small-cell lung cancer cells (NSCLC). Oncogene, 24(8), 1412-1422. doi:10.1038/ sj.onc. 1208333 .

158. Winn, R. A., Van Scoyk, M., Hammond, M., Rodriguez, K., Crossno, J. T., Jr., Heasley, L. E., et al. (2006). Antitumorigenic effect of Wnt $7 \mathrm{a}$ and Fzd 9 in non-small cell lung cancer cells is mediated through ERK-5-dependent activation of peroxisome proliferator-activated receptor gamma. Journal of Biological Chemistry, 281(37), 26943-26950. doi: 10.1074/jbc.M604145200.

159. Rhodes, D. R., Yu, J., Shanker, K., Deshpande, N., Varambally, R., Ghosh, D., et al. (2004). ONCOMINE: a cancer microarray database and integrated data-mining platform. Neoplasia, 6(1), 1-6.

160. Watanabe, T., Kobunai, T., Yamamoto, Y., Matsuda, K., Ishihara, S., Nozawa, K., et al. (2011). Differential gene expression signatures between colorectal cancers with and without KRAS mutations: crosstalk between the KRAS pathway and other signalling pathways. European Journal of Cancer, 47(13), 1946-1954. doi:10. 1016/j.ejca.2011.03.029.

161. Sayed, D., Rane, S., Lypowy, J., He, M., Chen, I. Y., Vashistha, H., et al. (2008). MicroRNA-21 targets Sprouty2 and promotes cellular outgrowths. Molecular Biology of the Cell, 19(8), 3272-3282. doi: 10.1091/mbc.E08-02-0159.

162. Thum, T., Gross, C., Fiedler, J., Fischer, T., Kissler, S., Bussen, M., et al. (2008). MicroRNA-21 contributes to myocardial disease by stimulating MAP kinase signalling in fibroblasts. Nature, 456(7224), 980-984. doi:10.1038/nature07511.

163. Huang, Z. P., Chen, J. F., Regan, J. N., Maguire, C. T., Tang, R. H., Dong, X. R., et al. (2010). Loss of microRNAs in neural crest leads to cardiovascular syndromes resembling human congenital heart defects. Arteriosclerosis, Thrombosis, and Vascular Biology, 30(12), 2575-2586. doi:10.1161/atvbaha.110.213306.

164. Bloethner, S., Chen, B., Hemminki, K., Muller-Berghaus, J., Ugurel, S., Schadendorf, D., et al. (2005). Effect of common BRAF and N-RAS mutations on global gene expression in melanoma cell lines. Carcinogenesis, 26(7), 1224-1232. doi:10.1093/carcin/ bgi066.

165. Quigley, D. A., To, M. D., Kim, I. J., Lin, K. K., Albertson, D. G., Sjolund, J., et al. (2011). Network analysis of skin tumor progression identifies a rewired genetic architecture affecting inflammation and tumor susceptibility. Genome Biology, 12(1), R5. doi:10.1186/ gb-2011-12-1-r5.

166. Mathieu, V., Pirker, C., Schmidt, W. M., Spiegl-Kreinecker, S., Lotsch, D., Heffeter, P., et al. (2012). Aggressiveness of human 
melanoma xenograft models is promoted by aneuploidy-driven gene expression deregulation. Oncotarget, 3(4), 399-413.

167. Baird, K., Davis, S., Antonescu, C. R., Harper, U. L., Walker, R. L., Chen, Y., et al. (2005). Gene expression profiling of human sarcomas: Insights into sarcoma biology. Cancer Research, 65(20), 9226-9235. doi:10.1158/0008-5472.can-05-1699.

168. Nielsen, T. O., West, R. B., Linn, S. C., Alter, O., Knowling, M. A., O'Connell, J. X., et al. (2002). Molecular characterisation of soft tissue tumours: a gene expression study. Lancet, 359(9314), 13011307. doi:10.1016/s0140-6736(02)08270-3.

169. Rathmanner, N., Haigl, B., Vanas, V., Doriguzzi, A., Gsur, A., \& Sutterluty-Fall, H. (2013). Sprouty2 but not Sprouty4 is a potent inhibitor of cell proliferation and migration of osteosarcoma cells. FEBS Letters, 587(16), 2597-2605. doi:10.1016/j.febslet.2013.06. 040.

170. Holtkamp, N., Mautner, V. F., Friedrich, R. E., Harder, A., Hartmann, C., Theallier-Janko, A., et al. (2004). Differentially expressed genes in neurofibromatosis 1-associated neurofibromas and malignant peripheral nerve sheath tumors. Acta Neuropathologica, 107(2), 159-168. doi:10.1007/s00401-0030797-8.

171. Courtois-Cox, S., Genther Williams, S. M., Reczek, E. E., Johnson, B. W., McGillicuddy, L. T., Johannessen, C. M., et al. (2006). A negative feedback signaling network underlies oncogene-induced senescence. Cancer Cell, 10(6), 459-472. doi:10.1016/j.ccr.2006. 10.003 .
172. Sanchez, A., Setien, F., Martinez, N., Oliva, J. L., Herranz, M., Fraga, M. F., et al. (2008). Epigenetic inactivation of the ERK inhibitor Spry2 in B-cell diffuse lymphomas. Oncogene, 27(36), 4969-4972. doi:10.1038/onc.2008.129.

173. Macia, A., Vaquero, M., Gou-Fabregas, M., Castelblanco, E., Valdivielso, J. M., Anerillas, C., et al. (2014). Sprouty1 induces a senescence-associated secretory phenotype by regulating NFkappaB activity: implications for tumorigenesis. Cell Death and Differentiation, 21(2), 333-343. doi:10.1038/cdd.2013.161.

174. Polytarchou, C., Iliopoulos, D., Hatziapostolou, M., Kottakis, F., Maroulakou, I., Struhl, K., et al. (2011). Akt2 regulates all Akt isoforms and promotes resistance to hypoxia through induction of miR-21 upon oxygen deprivation. Cancer Research, 71(13), 4720 4731. doi:10.1158/0008-5472.can-11-0365.

175. Moghaddam, S. M., Amini, A., Wei, A. Q., Pourgholami, M. H., \& Morris, D. L. (2012). Initial report on differential expression of sprouty proteins 1 and 2 in human epithelial ovarian cancer cell lines. Journal of Oncology, 2012, 373826. doi:10.1155/2012/ 373826.

176. Takahashi, M., Rhodes, D. R., Furge, K. A., Kanayama, H., Kagawa, S., Haab, B. B., et al. (2001). Gene expression profiling of clear cell renal cell carcinoma: gene identification and prognostic classification. [Comparative Study Research Support, Non-U.S. Gov't Validation Studies]. Proceedings of the National Academy of Sciences of the United States of America, 98(17), 9754-9759. doi:10.1073/pnas.171209998. 